\title{
Comparison of CALIPSO-Like, LaRC, and MODIS Retrievals of Ice-Cloud Properties over SIRTA in France and Florida during CRYSTAL-FACE
}

\author{
M. Chiriaco, ${ }^{*}$ H. Chepfer, ${ }^{*}$ P. Minnis, ${ }^{+}$M. Haeffelin, ${ }^{*}$ S. Platnick, ${ }^{\#}$ D. Baumgardner, \\ P. Dubuisson, \& M. McGill, ${ }^{\#}$ V. NoËl, ${ }^{+}$J. Pelon, $* *$ D. Spangenberg, ${ }^{+}+$S. Sun-Mack, \#\# \\ G.WIND@@ \\ * Laboratoire de Météorologie Dynamique, IPSL, Palaiseau, France \\ + NASA Langley Research Center, Hampton, Virginia \\ \# NASA Goddard Space Flight Center, Greenbelt, Maryland \\ ${ }^{\circledR}$ Universidad Nacional Autónoma de México, Mexico City, Mexico \\ ${ }^{\&}$ ELICO, Université du Littoral, Dunkerque, France \\ ** Service d'Aéronomie, IPSL, Paris, France \\ $++A S \& M$, Inc., Hampton, Virginia \\ \#\# SAIC, Hampton, Virginia

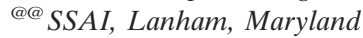

(Manuscript received 20 April 2005, in final form 28 October 2005)

\begin{abstract}
This study compares cirrus-cloud properties and, in particular, particle effective radius retrieved by a Cloud-Aerosol Lidar and Infrared Pathfinder Satellite Observation (CALIPSO)-like method with two similar methods using Moderate-Resolution Imaging Spectroradiometer (MODIS), MODIS Airborne Simulator (MAS), and Geostationary Operational Environmental Satellite imagery. The CALIPSO-like method uses lidar measurements coupled with the split-window technique that uses the infrared spectral information contained at the 8.65-, 11.15-, and $12.05-\mu \mathrm{m}$ bands to infer the microphysical properties of cirrus clouds. The two other methods, using passive remote sensing at visible and infrared wavelengths, are the operational MODIS cloud products (using 20 spectral bands from visible to infrared, referred to by its archival product identifier MOD06 for MODIS Terra) and MODIS retrievals performed by the Clouds and the Earth's Radiant Energy System (CERES) team at Langley Research Center (LaRC) in support of CERES algorithms (using 0.65-, 3.75-, 10.8-, and 12.05- $\mu \mathrm{m}$ bands); the two algorithms will be referred to as the MOD06 and LaRC methods, respectively. The three techniques are compared at two different latitudes. The midlatitude ice-clouds study uses 16 days of observations at the Palaiseau ground-based site in France [Site Instrumental de Recherche par Télédétection Atmosphérique (SIRTA)], including a ground-based 532-nm lidar and the MODIS overpasses on the Terra platform. The tropical ice-clouds study uses 14 different flight legs of observations collected in Florida during the intensive field experiment known as the Cirrus Regional Study of Tropical Anvils and Cirrus Layers-Florida Area Cirrus Experiment (CRYSTALFACE), including the airborne cloud-physics lidar and the MAS. The comparison of the three methods gives consistent results for the particle effective radius and the optical thickness but discrepancies in cloud detection and altitudes. The study confirms the value of an active remote sensing method (CALIPSO like) for the study of subvisible ice clouds, in both the midlatitudes and Tropics. Nevertheless, this method is not reliable in optically very thick tropical ice clouds, because of their particular microphysical properties.
\end{abstract}

\section{Introduction}

Ice clouds play a major role in the radiative energy budget of the earth-atmosphere system (Liou 1986; Stephens et al. 1990). Their impact is governed primar-

Corresponding author address: Marjolaine Chiriaco, Laboratoire de Météorologie Dynamique/IPSL, Ecole Polytechnique, 91128 Palaiseau CEDEX, France.

E-mail: chiriaco@lmd.polytechnique.fr ily by their opposing albedo and greenhouse effects, which are poorly known. The macrophysical and microphysical properties of ice clouds both determine these competing effects. The global coverage, altitude, temperature, vertical structure, and spatial inhomogeneities of these clouds must be accurately assessed to quantify their impact on weather and climate. In addition, ice water content and its spatial distribution are critical to the global radiative effect of cirrus clouds. A

DOI: $10.1175 / J A M 2435.1$ 
large uncertainty in evaluating the radiative impact of ice clouds arises from our limited knowledge of the natural variability of their microphysical properties, such as ice crystal size and shape, which determine their optical characteristics. For example, the effective radius of ice crystals composing cirrus clouds is an important microphysical parameter, because it largely affects cloud albedo, which increases with decreasing effective radius for a fixed ice water path. Reducing the uncertainties in both their macro- properties and their microphysical properties is essential for accurately defining the role of ice clouds in climate.

Satellite data are best suited for estimating ice-cloud properties because of their global coverage and longterm monitoring potential. Many remote sensing techniques have been devised to take advantage of the spectral radiances measured from various satellites to retrieve ice-cloud properties. The remote sensing methods have been complemented on a local scale by various midlatitude field experiments, such as the First International Satellite Cloud Climatology Project Regional Experiment (FIRE; Randall et al. 1996), the European Cloud and Radiation Experiment (Raschke et al. 1998), the International Cirrus Experiment (Raschke et al. 1990), and the Subsonic Aircraft: Contrail and Cloud Effects Special Study (SUCCESS; Toon and Miake-Lye 1998), as well as a few tropical campaigns such as the Central Equatorial Pacific Experiment (CEPEX; McFarquhar and Heymsfield 1996) and the recent Cirrus Regional Study of Tropical Anvils and Cirrus Layers-Florida Area Cirrus Experiment (CRYSTAL-FACE; Jensen et al. 2004), which have collected a valuable amount of in situ data that show significant variability of cirrus cloud particle sizes, either from one cloud to another or within a single cloud (Heymsfield 1975; Heymsfield and Platt 1984; Heymsfield 1993; Krupp 1991). Improved knowledge of realistic effective radii and shapes of ice crystals on the basis of in situ measurement has led to an improvement in the computation of the scattering properties of ice crystals (Wendling et al. 1979, Takano and Liou 1989; Mishchenko 1991; Macke et al. 1996; Yang and Liou 1996a,b; Yang et al. 2000; Havemann and Baran 2001). In parallel, various remote sensing retrieval techniques have been developed to infer the ice crystal effective radii from ground-based observations using active sensors (Platt et al. 1989; Intrieri et al. 1993, 1995; Mace et al. 1998; Matrosov 1999) and from satellite observations using passive sensors (Minnis et al. 1998; Baran et al. 1999; King et al. 2003, Platnick et al. 2003). In addition to improving the theoretical treatment of cloud optical properties, the in situ data are useful for understanding and evaluating the ground-based retrievals and, to some extent, the satellite retrievals. The ground-based retrievals can also be used for verifying the satellite passive remote sensing (e.g., Mace et al. 2005). It is also necessary, however, to determine the level of agreement between different remote sensing methods as another aspect of the uncertainties in the retrieved cloud properties.

A new retrieval algorithm recently developed for the Cloud-Aerosol Lidar and Infrared Pathfinder Satellite Observation (CALIPSO) mission (Winker et al. 2003) combines both passive and active sensors to retrieve ice particle effective radius. This hybrid technique (Chiriaco et al. 2004) will be implemented to create an operationally archived CALIPSO product. It will use collocated data from the three-channel $(8.7,10.5$, and $12 \mu \mathrm{m})$ CALIPSO Imaging Infrared Radiometer (IIR) and the 532-nm backscatter lidar operating with polarization capability on CALIPSO. Given the CALIPSO's launch on 28 April 2006, it is important to ensure that the technique operates as expected. The intent of this paper is to perform an initial validation of the ice particle effective radius retrieval algorithm developed for this instrument by Chiriaco et al. (2004) and to compare other relevant parameters such as optical thickness, cloud height, and cloud temperature. This new algorithm is applied to datasets of midlatitude ice clouds observed at the Site Instrumental de Recherche par Télédétection Atmosphérique (SIRTA; Haeffelin et al. 2005) in France and to datasets of tropical ice clouds observed during the 2002 CRYSTAL-FACE field campaign. The results of these retrievals are compared with two other methods that use passive remote sensing measurements from the Moderate-Resolution Imaging Spectroradiometer (MODIS) imager: the algorithm developed for the Clouds and Earth's Radiant Energy System (CERES) measurements by Minnis et al. (1995, 1998) and the algorithm developed as part of the operational MODIS cloud product (Platnick et al. 2003). The former method will be referred to as the Langley Research Center (LaRC) algorithm, while the latter is referred to as MOD06, which is the product identifier for the MODIS Terra cloud product in the National Aeronautics and Space Administration (NASA) Goddard Earth Sciences Distributed Active Archive Center (DAAC). LaRC retrievals for a CERES footprint are archived at the NASA Langley DAAC. Differences between MOD06 and a similar algorithm applied to the MODIS Airborne Simulator (MAS) data obtained during CRYSTAL-FACE will be discussed in section 2c. For CRYSTAL-FACE analysis, LaRC retrievals are applied to Geostationary Operational Environmental Satellite (GOES) imagery. In situ data taken during 
TABLE 1. Specifics of the CALIPSO-like, LaRC, and MOD06/MAS methods.

\begin{tabular}{|c|c|c|c|}
\hline & CALIPSO like & LaRC & MOD06/MAS \\
\hline Detection & Lidar $(532 \mathrm{~nm})$ & $\begin{array}{l}\text { Radiances }(0.65,3.75,10.8 \\
12.05 \mu \mathrm{m})\end{array}$ & $\begin{array}{l}\text { Radiances ( } 20 \text { bands between } 0.65 \\
\text { and } 13.3 \mu \mathrm{m})\end{array}$ \\
\hline Phase & Lidar depolarization $(532 \mathrm{~nm})$ & $\begin{array}{l}\text { Altitude }+ \text { temperature }+ \\
\text { radiances differences }(10.8-12.5 \\
\mu \mathrm{m})\end{array}$ & Radiances $(1.6,2.1,8.52,11 \mu \mathrm{m})$ \\
\hline Altitude/pressure & Lidar $(532 \mathrm{~nm})$ & $\begin{array}{l}\text { Temperature }+ \text { numerical weather } \\
\text { analyses }\end{array}$ & $\begin{array}{l}\text { Low cloud: radiances }(11 \mu \mathrm{m}) \\
\text { High clouds: } \mathrm{CO}_{2} \text {-slicing technique }\end{array}$ \\
\hline Temperature & $\begin{array}{l}\text { Lidar }(532 \mathrm{~nm})+\text { collocated } \\
\text { radiosonde }\end{array}$ & Radiances and optical thickness & $\begin{array}{l}\text { Pressure and numerical weather } \\
\text { analyses }\end{array}$ \\
\hline Optical thickness & $\begin{array}{l}\text { Visible: lidar }(532 \mathrm{~nm}) \\
\text { Infrared: comparison of } \\
\text { simulated and measured } \\
\text { radiances }(8.7,10.5,12 \mu \mathrm{m})\end{array}$ & $\begin{array}{l}\text { Radiances }(0.65,3.75,10.8, \\
12.05 \mu \mathrm{m})\end{array}$ & $\begin{array}{l}\text { Radiances }(0.65,0.86,1.2,1.6 \\
\quad 2.1,3.7 \mu \mathrm{m})\end{array}$ \\
\hline Effective radius & $\begin{array}{l}\text { lidar }(532 \mathrm{~nm})+\text { radiances }(8.7 \\
\quad 10.5,12 \mu \mathrm{m})\end{array}$ & Radiances $(3.75 \mu \mathrm{m})$ & $\begin{array}{l}\text { Radiances }(0.65,0.86,1.2,1.6,2.1, \\
\quad 3.7 \mu \mathrm{m})\end{array}$ \\
\hline Particles models & $\begin{array}{l}\text { Droplet }(6,12 \mu \mathrm{m}) \text { and crystals } \\
\quad\left(0.15<Q<9.26 \text { with } 0.5<r_{e}\right. \\
\quad<200 \mu \mathrm{m})\end{array}$ & $\begin{array}{l}\text { Droplets }(2<\text { re }<32 \mu \mathrm{m}) \text { and } \\
\quad \text { columns }\left(Q=2 \text { with } 3<r_{e}<\right. \\
\quad 67.5 \mu \mathrm{m})\end{array}$ & $\begin{array}{l}\text { Aggregates, bullet rosettes, hollow } \\
\text { columns, plates, with } \\
6<r_{e}<60 \mu \mathrm{m}\end{array}$ \\
\hline
\end{tabular}

CRYSTAL-FACE are also used to evaluate both the passive and CALIPSO-like algorithms.

\section{Three methods to retrieve ice-cloud properties}

\section{a. CALIPSO-like method}

The CALIPSO-like method retrieves ice-cloud properties given a set of measurements similar to those that are taken by CALIPSO: 532-nm lidar backscattering and brightness temperatures at 8.7, 10.5, and $12 \mu \mathrm{m}$. The effective radius $r_{e}$ initially corresponds to the radius of a sphere with a volume equivalent to that of the ice crystal, but it is corrected to be defined as

$$
r_{e}=\frac{3}{4} \frac{V}{A},
$$

where $V$ is the particle volume and $A$ is its projected area.

The method (Chiriaco et al. 2004) is based on the brightness temperature differences (BTD) between pairs of infrared channels measured from space. The BTD are compared with their counterparts computed for various ice crystal models based on effective radius and aspect ratio derived by Yang et al. (2001) with optical thicknesses ranging from 0 to 50 (Table 1). The brightness temperatures are computed using the Dubuisson et al. (2005) radiative transfer code. The CALIPSO-like method is a split-window technique improved by the lidar information: the cloud-base and cloud-top altitudes are derived from lidar; they are associated with a collocated radiosonde temperature profile leading to the cloud-top and cloud-base temperatures and allowing one to the temperature of the cold foot. This cold-foot temperature used to be a large uncertainty in the classical split-window technique. Then, for each cloud case studied, the surface and clear-sky atmospheric properties, as well as the observed cloud temperature at the altitude at which the lidar backscattered signal is maximal (Chiriaco et al. 2006), are prescribed in the radiative transfer code. This improvement strongly decreases the uncertainty on effective radius retrieval for semitransparent clouds (Chiriaco et al. 2004).

There are two ways to retrieve the cloud optical thickness using the CALIPSO-like method (Table 1): it can be retrieved just from lidar profile if the cloud optical thickness is less than 3 (all midlatitude cases in this study), or it can be retrieve by comparing the measured and simulated brightness temperatures-it is then an infrared optical thickness. This infrared optical thickness is used for the tropical cases in this study because they most of the time correspond to optical thickness larger than 3.

For a cloudy atmosphere, various microphysical parameters of particles are used to specify the cloud optical properties in the radiative transfer computations: spherical models and hexagonal models are used because the method requires optical properties in both the infrared domain [computation of the brightness temperatures using the radiative transfer code from Dubuisson et al. (1996) and using Yang et al. (2001) optical properties computation] and the visible domain [for the computation of the lidar depolarization ratio as a function of the particle aspect ratio from Noel et al. (2002)]. Particle models are defined with aspect ratios $Q=L /(2 R)$, where $L$ is the length of the crystal and $R$ 
is its radius: $Q<1$ are plates and $Q>1$ are columns. A class of $Q$ derived from the lidar depolarization with the method of Noel et al. (2002) is selected. Four $Q$ classes are defined to roughly segregate particles from the most to the least spherical: class I for $Q<0.05$, class II for $0.05<Q<0.7$, class III for $0.7<Q<1.1$, and class IV for $Q>1.1$. This constraint reduces the number of solutions, leading to an optimized selection of a microphysical model as defined by effective radius and particle aspect ratio.

\section{b. LaRC method}

The LaRC method was developed for application to operational meteorological satellite imagers for the Atmospheric Radiation Measurement Program (Ackerman and Stokes 2003) and for the research satellite imagers used by the CERES project. This method detects clouds and retrieves cloud properties using radiances measured at $0.65,3.75,10.8$, and $12.05 \mu \mathrm{m}$; effective particle radius information comes from the 3.75 $\mu \mathrm{m}$ band but, for ice clouds, is characterized using the effective ice crystal diameter $D_{e}$, which differs from the $r_{e}$ definition in (1). To compare effective radii from the different methods properly, the value of $D_{e}$ is converted to $r_{e}$ as

$$
r_{e}=0.0025\left(D_{e} / 2\right)^{2}+0.605\left(D_{e} / 2\right)
$$

This correction equation was derived using a regression fit between model values of $D_{e}$ and $r_{e}$ computed with (1) using $A$ and $V$. The model values of $D_{e}, A$, and $V$ were taken from Table 5 of Minnis et al. (1998).

The LaRC scene classification technique consists primarily of cascading threshold tests (Trepte et al. 2002). To define a pixel as cloudy, at least one of the spectral radiances must differ significantly from the corresponding expected clear-sky radiances. For a pixel classified as cloudy, the main algorithm used to retrieve cloud properties is the visible-infrared-solar-infrared-splitwindow technique (VISST), which is a four-channel upgrade of the three-channel method of Minnis et al. (1995). Given the clear-sky radiances and surface properties, the VISST computes the spectral radiances expected for both liquid-droplet and ice-water clouds for a range of optical thickness $\tau=0.25-128$ for a particular effective cloud temperature $T_{c}$ using a set of reflectance and emittance parameterizations (Minnis et al. 1998). The radiances are matched to the calculated values to determine $\tau, D_{e}$, and $T_{c}$. The thermodynamical phase is determined by a combination of tests that incorporate the final cloud temperature, the initially derived cloud altitude, and the 10.8-12.0- $\mu \mathrm{m}$ BTD. When the spectral data are available, the $1.6-/ 0.65-\mu \mathrm{m}$ reflectance ratio is also used in the phase decision. The effective cloud height is estimated from $T_{c}$ using vertical profiles of temperature from numerical weather analyses (NWA). Comparisons between a state-of-the-art NWA and radiosonde profiles yield average temperature biases of less than $0.5^{\circ} \mathrm{C}$ at cirrus altitudes (Minnis et al. 2005). Assuming lower-resolution NWA data have the same bias, the use of the NWA should yield an average underestimate of no more than $0.15 \mathrm{~km}$ in the effective height.

\section{c. MODIS operational method: MOD06}

The MOD06 uses several channels of the instrument ranging between 0.65 and $13.3 \mu \mathrm{m}$ (Platnick et al. 2003; King et al. 2003). The cloud mask uses a series of threshold tests to detect the presence of clouds with four confidence levels, with up to 20 bands from visible through infrared (Ackerman et al. 1998). For mid- to high-level clouds, the cloud-top pressure is retrieved using a carbon dioxide $\left(\mathrm{CO}_{2}\right)$-slicing technique (Menzel et al. 1983) that uses ratios of differences in radiances between cloudy and clear-sky regions at two nearby wavelengths. The cloud-top pressure uncertainty is estimated to be $50 \mathrm{hPa}$. For low-level clouds, the infraredwindow $11-\mu \mathrm{m}$-band temperature is used to determine a cloud-top temperature, assuming the cloud is optically thick, and a cloud-top pressure is assigned by comparing the measured brightness temperature with the National Centers for Environmental Prediction (NCEP) Global Data Assimilation System temperature profile (Derber et al. 1991). For the thermodynamical phase retrieval, the method uses the 8.52- and $11-\mu \mathrm{m}$ bands to exploit the spectral emission differences between water droplets and ice crystals (Baum et al. 2000) as well as ratios of the 1.6- and $2.1-\mu \mathrm{m}$ bands relative to visible and/or near-infrared bands (King et al. 2004). Cloud optical thickness and $r_{e}$ are estimated based on library calculations of plane-parallel homogeneous clouds overlying a black surface in the absence of atmosphere. Separate libraries exist for liquid water and ice clouds - the latter consisting of 12 size distributions (King et al. 2004) composed of four habits (Table 1), with the fraction of each habit in individual sizedistribution bins being a function of particle effective radius that is defined as follows:

$$
r_{e}=\frac{3}{4} \frac{\langle V\rangle}{\langle A\rangle} .
$$

This definition is equivalent to (1) but for crystals with the following size distribution: $\langle V\rangle$ is the mean particle volume for the ice crystal size distribution and $\langle A\rangle$ is the mean projected area. Scattering calculations are made using the techniques of Yang and Liou (1996a,b). 
TABLE 2. Cloud properties retrieved from three methods.

\begin{tabular}{lcccccccccccc}
\hline \hline & Phase & $T_{\text {top }}, T_{\text {bot }}$ & $T_{\text {eff }}$ & $z_{\text {top }}, z_{\text {bot }}$ & $z_{\text {eff }}$ & $P_{\text {top }}$ & $P_{\text {bot }}$ & $P_{\text {eff }}$ & $\tau$ & LWP, IWP & $r_{e, \text { ice }}, r_{e, \text { wat }}$ & Layers \\
\hline CALIPSO like & $\mathrm{x}$ & $\mathrm{x}$ & $\mathrm{X}$ & $\mathrm{x}$ & $\mathrm{x}$ & $\mathrm{x}$ & $\mathrm{x}$ & $\mathrm{x}$ & $\mathrm{x}$ & & & $\mathrm{x}$ \\
LaRC & $\mathrm{x}$ & $\mathrm{x}$ & $\mathrm{X}$ & $\mathrm{x}$ & $\mathrm{x}$ & $\mathrm{x}$ & $\mathrm{x}$ & $\mathrm{x}$ & $\mathrm{x}$ & $\mathrm{x}$ & $\mathrm{x}$ & \\
MOD06 (SIRTA) & $\mathrm{x}$ & $\mathrm{x}$ & & & & $\mathrm{x}$ & & & $\mathrm{x}$ & $\mathrm{x}$ & $\mathrm{x}$ & \\
MAS (CRYSTAL) & $\mathrm{x}$ & & & & & $\mathrm{x}$ & & & $\mathrm{x}$ & $\mathrm{x}$ & $\mathrm{x}$ & $\mathrm{x}$ \\
\hline
\end{tabular}

Table 2 shows the differences between the products available for the SIRTA cases and the CRYSTALFACE cases. The MOD06 retrievals over SIRTA use MODIS Terra data and are archived at the NASA Goddard DAAC. The CRYSTAL-FACE cases are processed independently using radiances from the MAS that flew on the NASA ER-2 aircraft. The MAS retrievals are based on the retrieval method of Platnick et al. (2001) and use ice libraries similar to those described above for MOD06, but with two distinctions. First, new scattering calculations for the 12 distributions were made using MAS-specific spectral bandpasses. Second, a quadratic polynomial was fitted to all scattering parameters (single scattering, albedo, asymmetry parameter, and extinction efficiency) as a function of the 12 size distributions to smooth out nonmonotonic behavior with particle effective radius. Then, reflectance libraries were calculated at equal intervals in interpolated $r_{e}$ space $(5,10, \ldots 55,60 \mu \mathrm{m})$. The MAS products include a map of apparent multilayer clouds that provides information on the confidence of the retrievals. Because MAS is a spectrometer, the phase algorithm for MAS includes additional tests that are derived from the location of the MAS band corresponding to the peak reflectance in the 1.6- and 2.1- $\mu \mathrm{m}$ spectral regions (Pilewskie and Twomey 1987). Last, the MAS cloud-top-property retrievals are not derived from a $\mathrm{CO}_{2}$-slicing technique because of insufficient signal to noise in these bands during the experiment but rather from an algorithm that uses path absorption in the $0.94-\mu \mathrm{m}$ water vapor band. NCEP profiles are used to convert the inferred above-cloud vapor amount to cloud-top pressure and temperature.

\section{Midlatitude ice clouds: SIRTA cases}

\section{a. Observations: Instruments and dates}

The SIRTA observatory sits on a $10-\mathrm{km}$ plateau about $160 \mathrm{~m}$ above sea level. The plateau is a semiurban environment divided equally into agricultural fields, wooded areas, and housing and industrial developments. Sixteen midlatitude cloud cases observed at the SIRTA ground-based site are investigated using observations collected with the instruments listed below.

\section{1) MODIS TERRA}

Depending on the orbit, MODIS on Terra observes Palaiseau, France, 1 or 2 times per day. Although higher-resolution data are available for selected channels, the nominal MODIS resolution is $1 \mathrm{~km}$ for all 36 channels. Those data are used in each of the three methods, and the pixel areas used for the application are described in Table 3. For all retrievals except MOD06 cloud-top pressure and temperature, the sample of pixels is a strip with a width of three pixels (i.e., $3 \mathrm{~km}$ ) and a length of $1 \mathrm{~h}$ centered on the SIRTA overpass time (using wind information from radiosonde at the cloud altitude from lidar); for this sample, data are corrected for parallax using the cloud altitude from lidar and the wind speed from radiosonde. For the MOD06 pressure and temperature retrievals, the sample used is a box of $5 \times 5$ pixels (i.e., $5 \times 5 \mathrm{~km}^{2}$ ) over SIRTA, because this product is only available at this resolution.

\section{2) GROUND-BASED 532-NM LIDAR}

The SIRTA 532-nm lidar is similar to the one that is on the CALIPSO platform. It operates 4 days week $^{-1}$ from 0800 to 2000 local time, with a nominal temporal resolution of $10 \mathrm{~s}$ (an average of 200 shots) and a vertical resolution of $15 \mathrm{~m}$. It is a zenith-viewing lidar that measures both the backscattered signal and the linear depolarization ratio. The lidar observations are treated as follows: 1) the parallel-polarized signal at $532 \mathrm{~nm}$ is normalized to the molecular signal deduced from the radiosonde profiles (described below), 2) the cloudbase and cloud-top altitudes are derived from lidar profiles averaged over $1 \mathrm{~min}$ in the parallel channel using a threshold method, and 3 ) the linear depolarization ratio is the ratio of the perpendicular channel to the parallel channel and it is normalized to $2.8 \%$ (Young 1980) in a cloud-free area, that is, where there are only atmospheric molecules.

\section{3) Météo-France Radiosondes}

The temperature profiles are obtained by radiosondes launched every day between 1100 and 1200 UTC from the Trappes, France, station located $15 \mathrm{~km}$ 
away from the SIRTA site, as part of the Météo-France operational network, . The maximal time difference between the studied part of the cloud (at the time at which Terra overpasses the SIRTA) is $1 \mathrm{~h}$; hence, one can consider that the temperature is stable during this lapse of time.

The studied cases were selected using lidar information. Ice clouds were identified using the depolarization ratio based on the behavior of nonspherical particles (i.e., ice crystals) that strongly depolarize the signal. Furthermore, the boundaries of thin ice clouds are determined from the lidar backscattered signal when both cloud bottom and top are evident in the returns. Only those clouds that are relatively constant $( \pm 30 \mathrm{~min}$ around the satellite overpass) in time and space are selected to facilitate good collocation between the lidar and the satellite measurements. A total of 18 different days of observations have been analyzed. Table 4 summarizes the dates and time periods of observations for the different instruments as well as the cloud altitudes.

\section{b. Comparison of the three methods}

\section{1) Illustrative case: 8 OCtober 2002}

Figure 1a shows the evolution of the 532-nm lidar depolarization ratio with time and altitude. This image indicates a cloud located between 6.5 and $11 \mathrm{~km}$ with a relatively constant altitude, making it a good case study. The depolarization ratios range between $20 \%$ and $60 \%$ within the cloud, indicating that it is an ice cloud because nonspherical particles strongly depolarize the signal and an ice cloud is composed of nonspherical particles. Figure $1 \mathrm{~b}$ shows a pseudocolor image of the area based on the 0.6-, 1.6-, and 11- $\mu \mathrm{m}$ MODIS channels. Pixels from this image were collocated with the lidar measurements corresponding to the time at which Terra passed over the SIRTA site (center of the red square) at 1105 UTC. The length of the strip of pixels used for the retrieval is calculated as follows: each pixel is at a distance $d$ from the SIRTA pixel, the horizontal wind $(U, V)$ at the cloud altitude is known from the radiosonde, and the time at which the pixel passes over the SIRTA is calculated from $d$ and $(U, V)$. The pixel strip selected for the retrieval is $1 \mathrm{~km}$ wide and corresponds to $\pm 30 \mathrm{~min}$ centered on the SIRTA site. This strip is represented with red lines in Fig. 1a. For this case, $U=5.79 \mathrm{~m} \mathrm{~s}^{-1}$ and $V=2.43 \mathrm{~m} \mathrm{~s}^{-1}$ at the altitude of cloud center, and so the strip length is approximately $22 \mathrm{~km}$. Figure $1 \mathrm{c}$ shows the cloud phase retrieved from the LaRC method. In the red square centered on the SIRTA site, most of pixels are ice clouds, with a few pixels of water cloud or clear sky near the cloud edges. 
TABLE 4. Midlatitude ice-clouds case: " $b$ " subscript is "base," " $T$ " subscript is "top," and " $e$ " subscript is "effective." Optical thickness is visible.

\begin{tabular}{|c|c|c|c|c|c|c|c|c|c|c|}
\hline \multirow[b]{2}{*}{ Date } & \multirow[b]{2}{*}{ UTC } & \multirow{2}{*}{$\begin{array}{c}\text { Skin } \\
\text { temperature } \\
(\mathrm{K})\end{array}$} & \multicolumn{3}{|c|}{ CALIPSO like } & \multicolumn{2}{|c|}{ LaRC } & \multicolumn{2}{|c|}{ MOD06 } & \multirow[b]{2}{*}{ Comments } \\
\hline & & & $\begin{array}{c}Z_{b}(\mathrm{~km}) \\
T_{b}(\mathrm{~K})\end{array}$ & $\begin{array}{c}Z_{T}(\mathrm{~km}), \\
T_{T}(\mathrm{~K})\end{array}$ & $\tau_{\text {lidar }}$ & $\begin{array}{c}z_{e}(\mathrm{~km}), \\
T_{e}(\mathrm{~K})\end{array}$ & $\tau_{\text {ice }}$ & $\begin{array}{c}z_{T}(\mathrm{~km}), \\
T_{T}(\mathrm{~K})\end{array}$ & $\tau_{\text {ice }}$ & \\
\hline \multirow[t]{2}{*}{5 Mar 2002* } & 1110 & 281 & 7.3 & 9.5 & $0.8-1$ & 7.7 & 0.8 & 9.9 & 1.4 & LaRC: two ice layers \\
\hline & & & 234 & 214 & & 238 & & 217 & & MOD06: ice \\
\hline \multirow[t]{2}{*}{1 Oct $2002 *$} & 1055 & 290 & 8.8 & 10.7 & $1-4$ & 8.8 & 2.2 & 10.1 & 2.6 & $\begin{array}{l}\text { LaRC: ice and liquid } \\
\text { water }\end{array}$ \\
\hline & & & 236 & 219 & & 235 & & 225 & & MOD06: ice \\
\hline \multirow[t]{2}{*}{8 Oct $2002 *$} & 1105 & 285 & 6.1 & 11 & $1.4-3$ & 7 & 1.8 & 9.7 & 2.2 & $\begin{array}{l}\text { LaRC: ice and liquid } \\
\text { water }\end{array}$ \\
\hline & & & 251 & 214 & & 244 & & 222 & & MOD06: ice \\
\hline \multirow[t]{2}{*}{6 Nov $2002 *$} & 1030 & 282 & 6.9 & 10.7 & $0.4-1.2$ & 6.3 & 2.4 & 10.9 & 3.2 & $\begin{array}{l}\text { LaRC: ice and liquid } \\
\text { water }\end{array}$ \\
\hline & & & 247 & 222 & & 250 & & 217 & & MOD06: ice \\
\hline \multirow[t]{2}{*}{19 Dec 2002* } & 1015 & 273 & 8.6 & 12 & $0.8-1.2$ & 6.8 & 0.9 & 10.4 & 1.3 & LaRC: two ice layers \\
\hline & & & 230 & 202 & & 239 & & 214 & & MOD06: ice \\
\hline \multirow[t]{2}{*}{19 Dec 2002} & 1150 & 274 & 10.3 & 11.9 & $0.2-0.3$ & 6.8 & 0.3 & No cloud & 1 & LaRC: four ice layers \\
\hline & & & 216 & 202 & & 235 & & & & MOD06: \\
\hline \multirow[t]{2}{*}{19 Feb 2003} & 1025 & 271 & 8.8 & 10.2 & 0.2 & No i & & No & & LaRC: liquid water \\
\hline & & & 223 & 211 & & & & & & MOD06: liquid water \\
\hline \multirow[t]{2}{*}{24 Feb 2003} & 1040 & 283 & 7.5 & 8.7 & $0-0.1$ & 2.2 & 0.3 & No c & oud & $\begin{array}{l}\text { LaRC: ice and liquid } \\
\text { water }\end{array}$ \\
\hline & & & 234 & 225 & & 264 & & & & MOD06: no cloud \\
\hline \multirow[t]{2}{*}{17 Mar 2003} & 1100 & 284 & 6.8 & 7.8 & 0.1 & 3.6 & 0.4 & No cloud & 1 & $\begin{array}{l}\text { LaRC: ice and liquid } \\
\text { water }\end{array}$ \\
\hline & & & 238 & 231 & & 257 & & & & MOD06: ice \\
\hline \multirow[t]{2}{*}{27 Mar 2003} & 1140 & 291 & 9.8 & 10.1 & 0.06 & No clc & & No c & oud & $\begin{array}{l}\text { LaRC and MODIS: } \\
\text { no cloud }\end{array}$ \\
\hline & & & 220 & 214 & & & & & & \\
\hline \multirow[t]{2}{*}{1 Apr 2003* } & 1020 & 288 & 9.4 & 10.7 & $0.15-0.8$ & 7.4 & 1.3 & No ice & 1.7 & $\begin{array}{l}\text { LaRC: ice and liquid } \\
\text { water }\end{array}$ \\
\hline & & & 224 & 214 & & 239 & & & & $\begin{array}{l}\text { MOD06: ice and } \\
\text { liquid water }\end{array}$ \\
\hline \multirow[t]{2}{*}{9 Sep 2003* } & 1100 & 292 & 9.2 & 10.1 & $0.09-0.1$ & 6.6 & 1.3 & 16.4 & 1.8 & $\begin{array}{l}\text { LaRC: ice and liquid } \\
\text { water }\end{array}$ \\
\hline & & & 230 & 224 & & 248 & & $?$ & & $\begin{array}{l}\text { MOD06: ice and } \\
\text { liquid water }\end{array}$ \\
\hline \multirow[t]{2}{*}{15 Sep 2003} & 1200 & 295 & 11.7 & 12 & 0.03 & No clc & & No c & oud & $\begin{array}{l}\text { LaRC and MODIS: } \\
\text { no cloud }\end{array}$ \\
\hline & & & 220 & 218 & & & & & & \\
\hline \multirow[t]{2}{*}{6 Nov 2003} & 1140 & 287 & 10.3 & 11.2 & $0-0.1$ & No clc & & 11.3 & No cloud & $\begin{array}{l}\text { LaRC and MODIS: } \\
\text { no cloud }\end{array}$ \\
\hline & & & 225 & 217 & & & 218 & & & \\
\hline \multirow[t]{2}{*}{17 Nov 2003* } & 1120 & 282 & 9.3 & 11.2 & $0.05-0.1$ & 5.6 & 0.6 & No cloud & 2.8 & $\begin{array}{l}\text { LaRC: ice and } \\
\text { liquid water }\end{array}$ \\
\hline & & & 227 & 213 & & 249 & & & & $\begin{array}{l}\text { MOD06: ice and } \\
\text { liquid water }\end{array}$ \\
\hline \multirow[t]{2}{*}{9 Dec 2003} & 1040 & 278 & 9.3 & 11.2 & $0.1-0.2$ & 2.5 & 0.3 & \multirow{2}{*}{\multicolumn{2}{|c|}{ No cloud }} & $\begin{array}{l}\text { LaRC: ice and liquid } \\
\text { water }\end{array}$ \\
\hline & & & 227 & 213 & & 261 & & & & MOD06: no cloud \\
\hline
\end{tabular}

* When the comparison of the three methods is possible (semitransparent cloud for CALIPSO-like technique and ice cloud found for LaRC and MOD06 techniques).

Table 5 shows the results of the retrievals using the three methods. The MOD06 cloud-top altitude is derived from the MOD06 cloud-top pressure and the radiosonde. The three methods give consistent altitudes and temperatures, even if the MOD06 and LaRC techniques show a cloud top under the lidar one (respectively, 1.3 and $2.3 \mathrm{~km}$ lower) that is detected with no ambiguity because the cloud has optical thickness less 

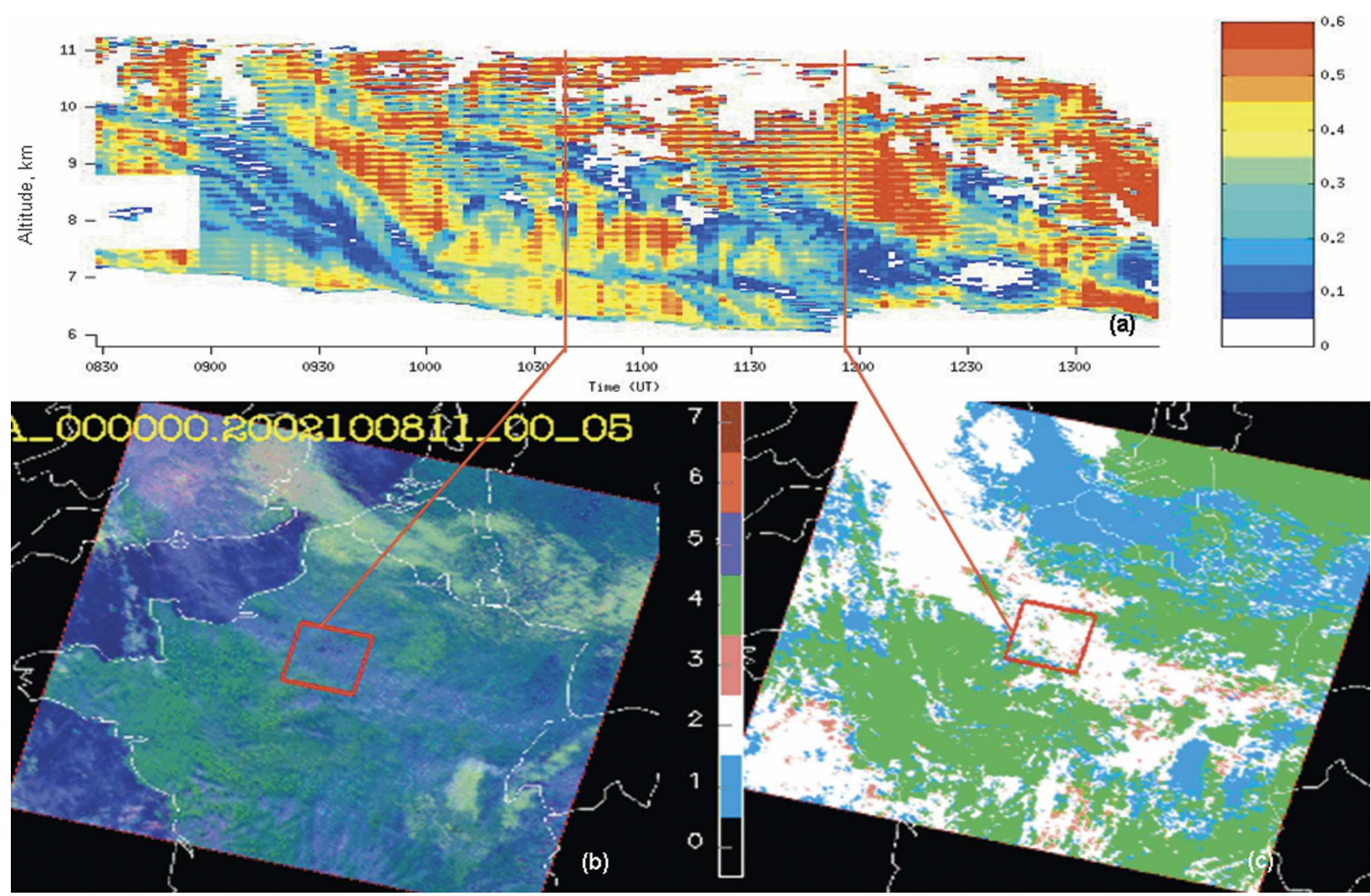

FIG. 1. 8 Oct 2002: (a) lidar depolarization ratio, (b) composite image using 0.6-, 1.6-, 11- $\mu \mathrm{m}$ channels from the LaRC retrieval using MODIS data at 1105 UTC, and (c) LaRC cloud phase (1: water cloud, 2: ice cloud, 3: no retrieval, 4: clear, 5: bad data, 6: no retrieval water cloud, and 7: no retrieval ice cloud). SIRTA area is the center of red square.

than 3, meaning that the lidar still detects molecules above the cloud. The mean effective cloud altitude given by the LaRC method is $0.8 \mathrm{~km}$ under the lidar one (CALIPSO like). The effective temperature refers to the radiative equivalent temperature of the cloud and is typically below cloud center for optically thin ice clouds. The visible optical thicknesses obtained with the three methods are consistent, ranging between 1.3 and 3. For such a semitransparent cloud, the CALIPSO-like method uses the lidar-based optical thickness, which is corrected from multiple scattering whatever the particles' size and shape with the method of Platt (1973) and Chepfer et al. (1999) and using $\eta=$ 0.5 (where $\eta$ is the ratio of apparent visible extinction coefficient to true visible extinction coefficient). The particle effective radii are consistent between the CALIPSO-like and LaRC methods, but the MOD06 effective radius is almost 2 times the CALIPSO-like one: this will lead to different impact on radiative transfer because, for example, a cloud with constant ice water content but a particle size divided by 2 has an albedo that increases by $20 \%-30 \%$ (Stephens et al. 1990). Last, the CALIPSO-like method gives a smaller result. The MOD06 and CALIPSO-like methods give a larger variability (respectively, 23 and $16 \mu \mathrm{m}$ ) than the LaRC method $(9 \mu \mathrm{m})$.

\section{2) All SIRTA cases}

All of the 18 SIRTA cases are studied in the manner of the 8 October 2002 case. Before any interpretation, it

TABLE 5. Results of the three retrieval methods for 8 Oct 2002 case. Optical thickness is visible.

\begin{tabular}{lcccc}
\hline \hline \multicolumn{1}{c}{ Method } & Altitude $(\mathrm{km})$ & Temperature $(\mathrm{K})$ & Optical thickness & Particle effective radius $(\mu \mathrm{m})$ \\
\hline CALIPSO like & $6.1-11$ & $251-214$ & $1.4-3.0$ & $6-22$ \\
LaRC & $6.9-8.7$ & $245-231$ & $1.3-2.1$ & $14.5-23.5$ \\
MOD06 & 9.7 (top) & 222 (top) & $1.7-2.7$ & $14-37$ \\
\hline
\end{tabular}




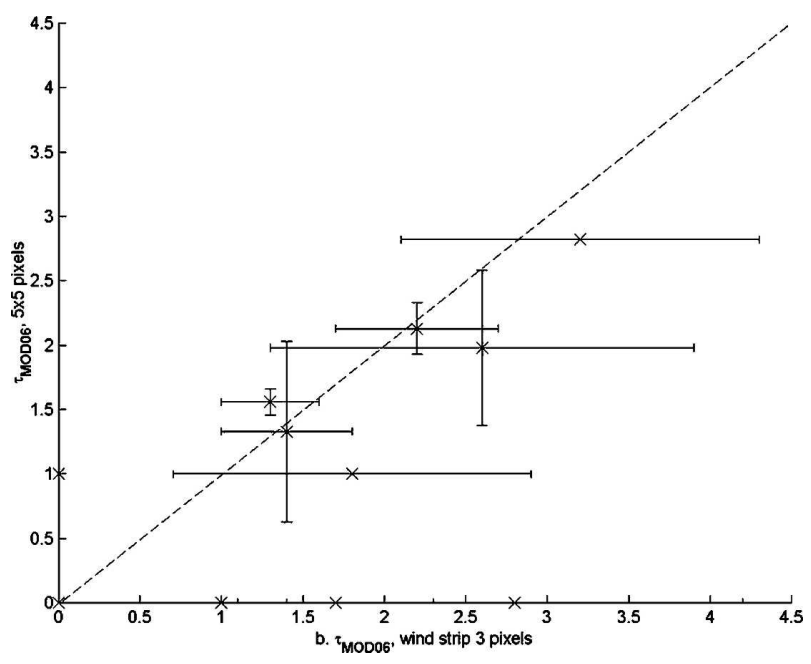

FIG. 2. The $\tau_{\text {MODO6 }}$ retrieved in the $5 \times 5$ pixel area against $\tau_{\text {MOD06 }}$ retrieved in the 3-pixel-large wind strip, for SIRTA cases. Error bars are standard deviations calculated in the sample of pixels. is necessary to note that the MOD06 altitudes and temperatures given in Table 4 do not use the same sample of pixels as do all of the other products. One consequence is that for five cases, the MOD06 technique does not detect any ice cloud using the $5 \times 5$ pixel sample (the one used for altitude and temperature retrievals), whereas there is an ice cloud using the pixel strip sample (the one used for the other retrievals: optical depth, effective radius, liquid/ice water path). Figure 2 is the MOD06 optical thickness retrieved from the $5 \times 5$ pixel sample against the one retrieved from the pixel strip sample, when both lead to ice cloud. For three cases out of six, the result is different and illustrates the variability that must be taken into account in the comparison of cloud temperatures and altitudes from the different methods.

In all cases, the CALIPSO-like method detects ice clouds only. For six cases in 2003 (19 and 24 February, 27 March, 15 September, 6 November, and 9 Decem-

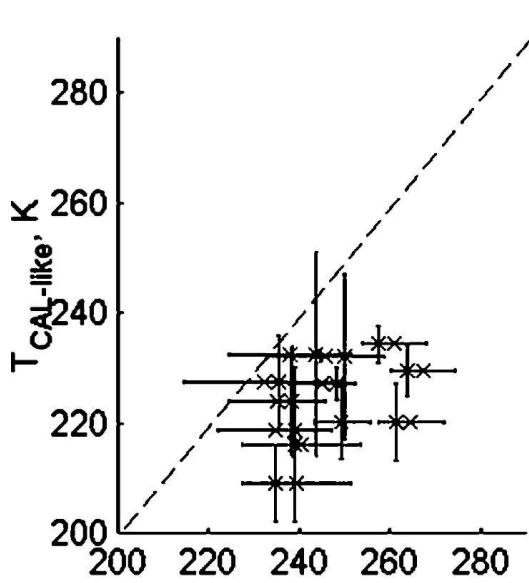

a. $T_{\text {LARC }}, \mathrm{K}$

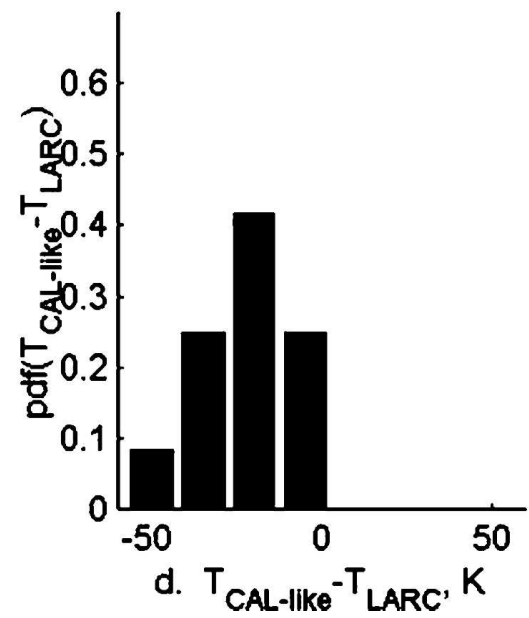

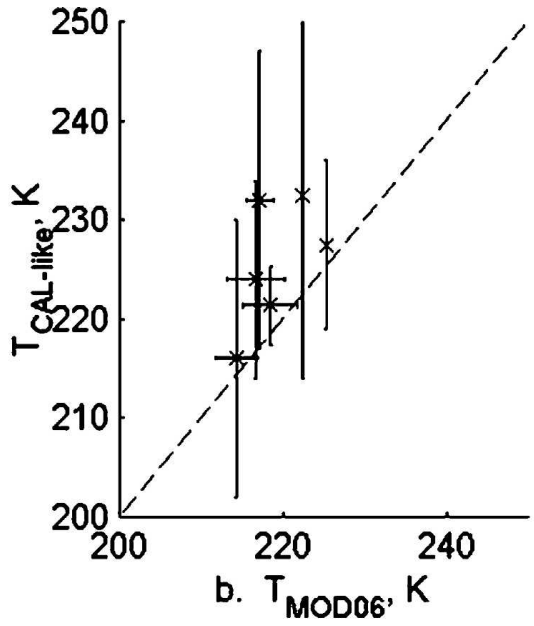
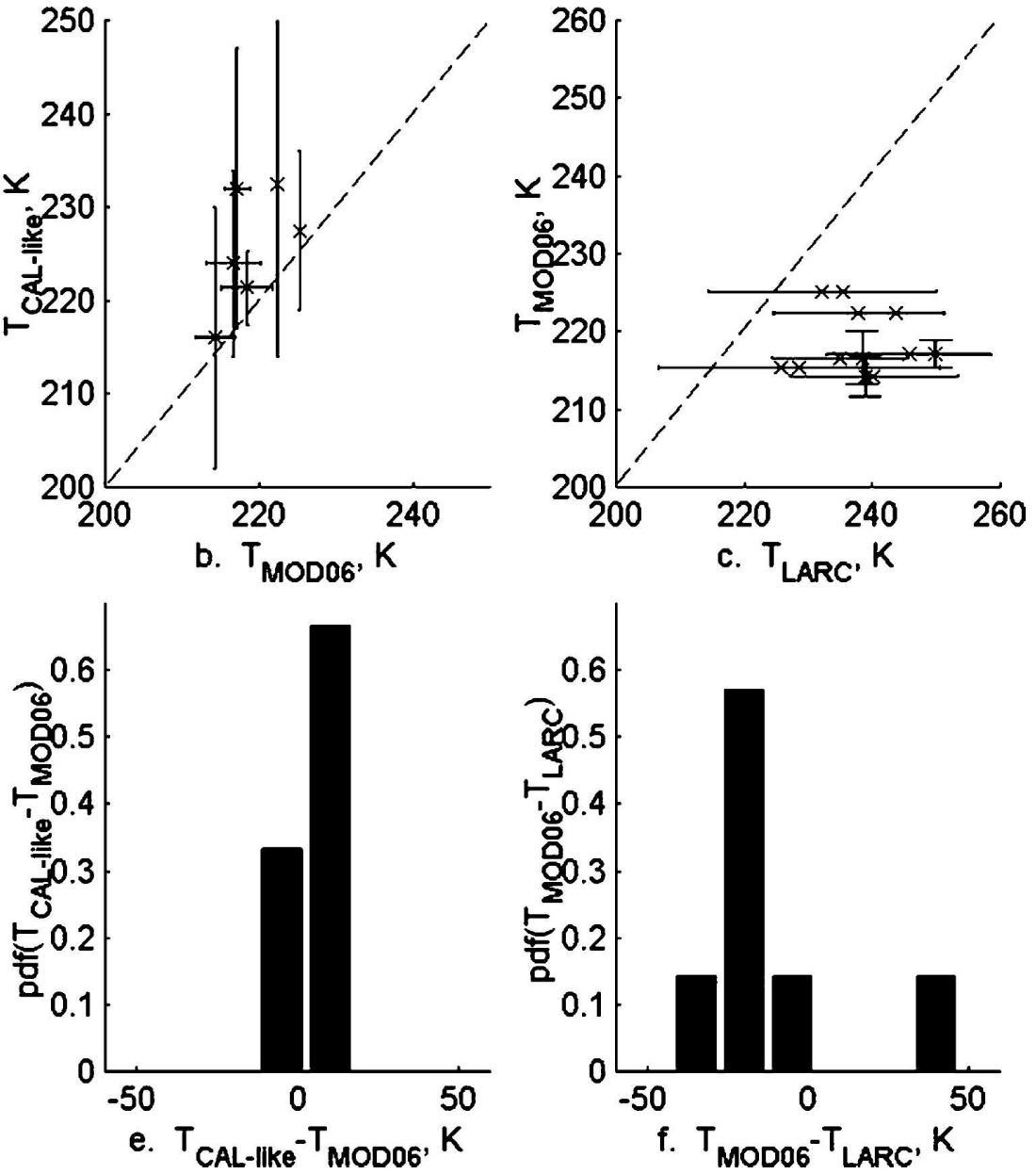

FIG. 3. SIRTA cloud cases: (a) $T_{\mathrm{CAL}-\text { like }}=f\left(T_{\mathrm{LaRC}}\right)$, (b) $T_{\mathrm{CAL}-\text { like }}=f\left(T_{\mathrm{MOD} 06}\right)$, (c) $T_{\mathrm{MOD} 06}=f\left(T_{\mathrm{LaRC}}\right)$, (d) PDF of $T_{\mathrm{CAL}-\text { like }}-$ $T_{\mathrm{LaRC}}$, (e) PDF of $T_{\mathrm{CAL}-\mathrm{like}}-T_{\mathrm{MOD} 06}$, and (f) PDF of $T_{\mathrm{MOD} 06}-T_{\mathrm{LaRC}}$. Dashed lines are $x=y$. 

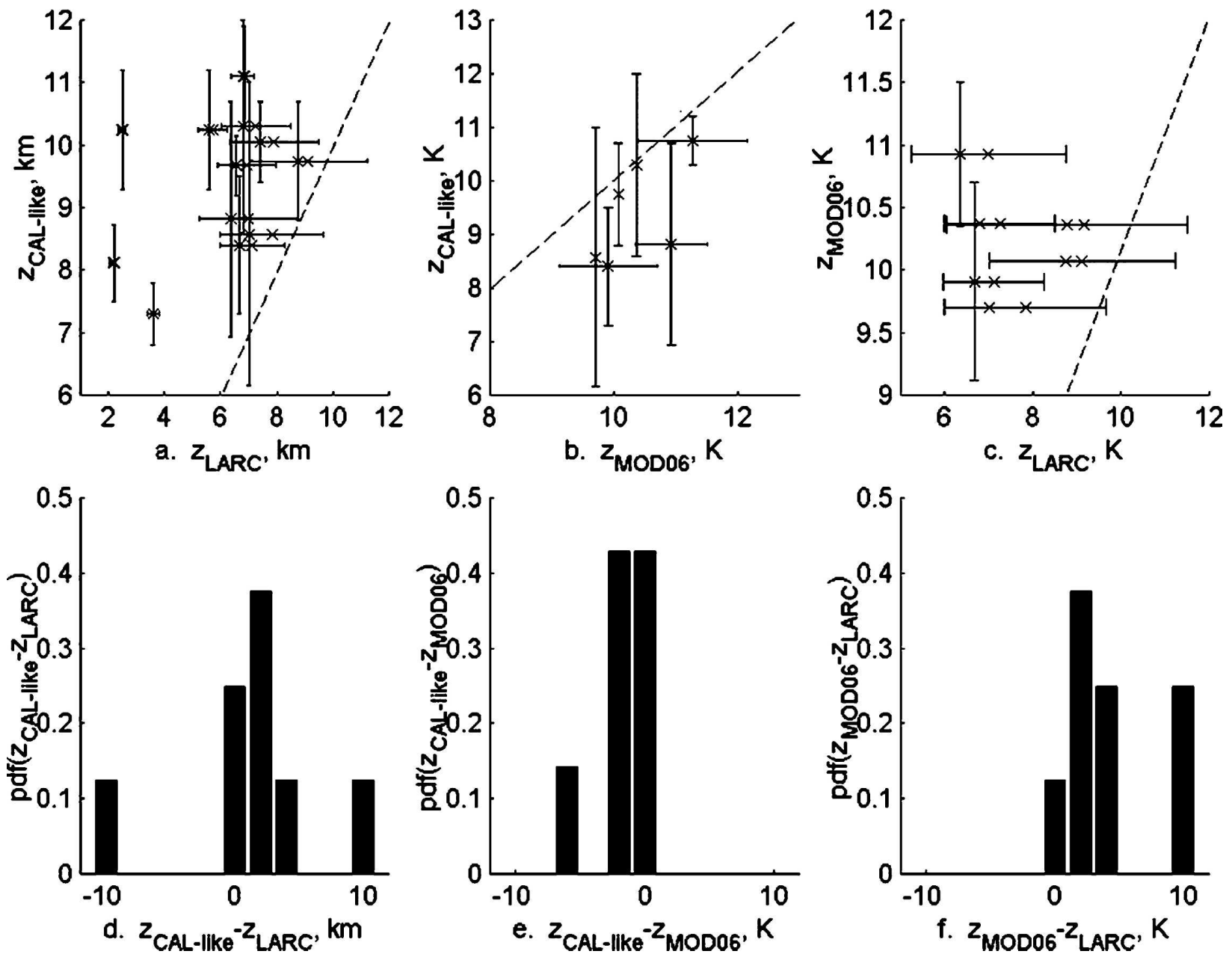

FIG. 4. SIRTA cloud cases: (a) $z_{\text {CAL-like }}=f\left(z_{\text {LaRC }}\right)$, (b) $z_{\text {CAL-like }}=f\left(z_{\text {MOD06 }}\right)$, (c) $z_{\text {MOD06 }}=f\left(z_{\text {LaRC }}\right)$, (d) PDF of $z_{\text {CAL-like }}-$ $z_{\mathrm{LaRC}}$, (e) PDF of $z_{\mathrm{CAL}-\text { like }}-z_{\mathrm{MOD} 06}$, and (f) PDF of $z_{\text {MOD06 }}-z_{\mathrm{LaRC}}$. Dashed lines are $x=y$.

ber), the cloud is too thin for the MOD06 method to detect clouds along the wind strips. The same thing is observed for four cases using the LaRC method (19 February, 27 March, 15 September, and 6 November). Those days were selected specifically because the lidar detects subvisible ice clouds with optical thicknesses smaller than 0.2. The 10 remaining cases are used to compare cloud altitude, optical thickness, and effective radius. The clouds are identified as mixed water and ice by the LaRC method in nine instances and by the MOD06 method in three instances, whereas the clouds are only ice from the CALIPSO-like method. Examination of the imagery reveals that low-level clouds are present in the vicinity for 1 and 8 October and could easily have been included in the pixel strips because of the parallax and advection corrections, which would not be properly applied for low clouds. No low clouds were evident for the 9 December case, which mostly consisted of contrails. For the 6 November
2002 case, the LaRC method retrieves both ice and water clouds. The imagery (not shown) reveals the presence of an extensive, broken, low cloud deck. The "comments" column of Table 4 indicates when the LaRC and MOD06 methods find several ice or water pixels (a single pixel being associated with one phase only).

Comparisons for the 10 clouds for which the lidar optical thickness exceeds 0.3 are shown in Figs. 3-7. Figure 3a shows the scatterplot of cloud temperature retrieved with the CALIPSO-like method $\left(T_{\text {CAL-like }}\right)$ as a function of the LaRC-retrieved-temperature method $\left(T_{\mathrm{LaRC}}\right)$. In the graph, the variability is the difference between the cloud top and bottom, and the LaRC cloud effective temperature is the cross on error bars. Figure $3 \mathrm{~d}$ is the probability density function (PDF) of the difference between CALIPSO-like and LaRC cloud temperatures. Those two figures show that $T_{\mathrm{CAL} \text {-like }}$ is always less than $T_{\mathrm{LaRC}}$, even if they are very close for 

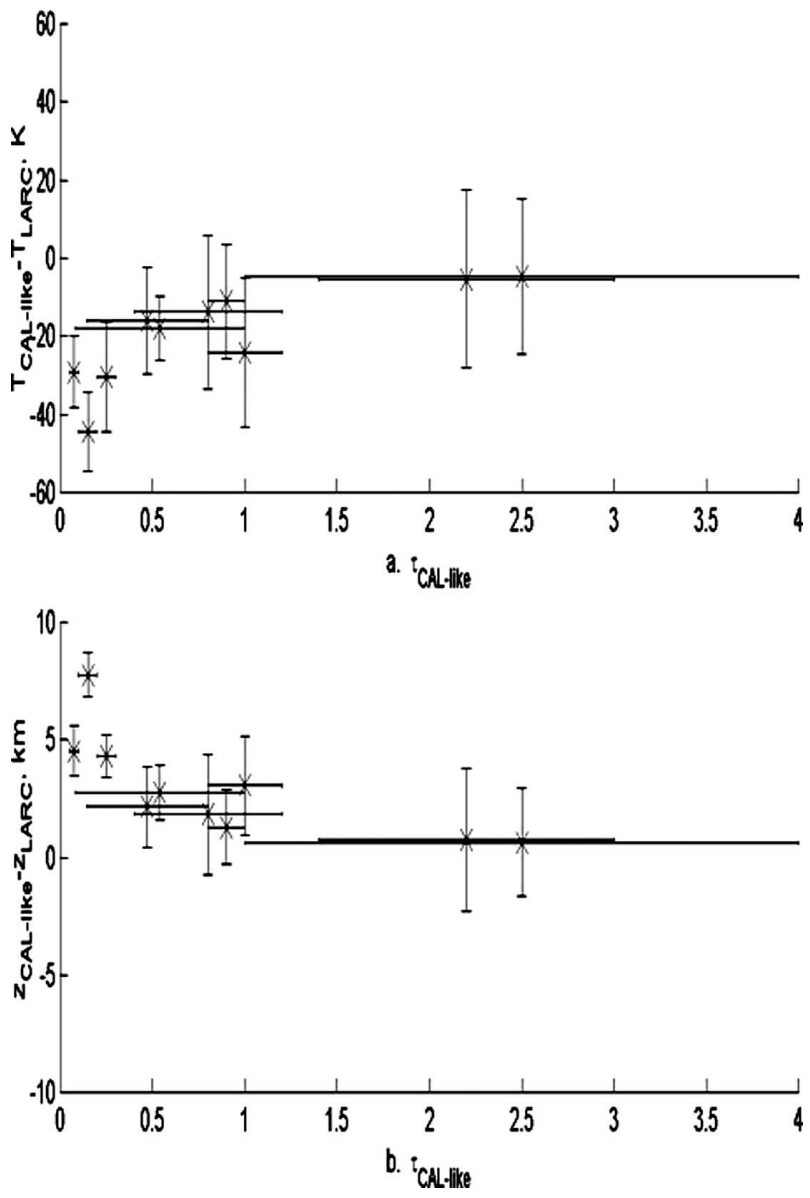

FIG. 5. SIRTA cloud cases: (a) $T_{\text {CAL-like }}-T_{\text {LaRC }}=f\left(\tau_{\text {CAL-like }}\right)$ and (b) $z_{\text {CAL-like }}-z_{\text {LaRC }}=f\left(\tau_{\text {CAL-like }}\right)$.

cases in which the CALIPSO-like optical thickness $\left(\tau_{\text {CAL-like }}\right)$ ranges from 0.8 to 1 . Figure $3 \mathrm{~d}$ shows that for $75 \%$ of cases the difference between $T_{\text {CAL-like }}$ and $T_{\mathrm{LaRC}}$ is larger than $20 \mathrm{~K}$ and that for $25 \%$ of cases the difference is between 0 and $20 \mathrm{~K}$. The greatest difference, $35 \mathrm{~K}$, occurs on 9 September 2003 and is associated with a subvisible cloud with $\tau_{\text {CAL-like }}$ ranging between 0.09 and 0.1 (Table 4). Figure $3 \mathrm{~b}$ is the comparison between the CALIPSO-like temperatures and the MOD06 ones when MOD06 using the $5 \times 5$ pixel sample finds an ice cloud. Because the MOD06 data are only available for the cloud top, their variability is a standard deviation calculated in the sample. We must compare them with the lowest point of CALIPSO-like error bars: it shows that the agreement is very good, even if $T_{\text {CAL-like }}$ is most of the time (70\%) greater than $T_{\text {MOD06 }}$ as shown by Fig. 3e. The comparison between $T_{\text {MOD06 }}$ and $T_{\text {LaRC }}$ (Figs. 3c,f) is consistent with the other ones: $T_{\mathrm{LaRC}}$ is always warmer than $T_{\mathrm{MOD} 06}$, showing that the $\mathrm{CO}_{2}$-slicing technique used for the MOD06 method performs better.
The results for altitudes (Fig. 4) are consistent with the ones obtained for temperatures: for most of the cases $z_{\text {CAL-like }}$ is greater than $z_{\mathrm{LaRC}}$, except for one case in which $T_{\mathrm{CAL} \text {-like }}=T_{\mathrm{LaRC}}(5$ March 2002). The greatest difference between $z_{\mathrm{CAL}-\text { like }}$ and $z_{\mathrm{LaRC}}$ is $6.5 \mathrm{~km}$ and corresponds to 17 November 2003, when $\tau_{\text {CAL-like }}$ varied from 0.05 to 1 . As for the temperature, the agreement is better between the CALIPSO-like and MOD06 methods.

Figure $5 \mathrm{a}$ shows the variations of $T_{\mathrm{CAL}-\text { like }}-T_{\mathrm{LaRC}}$ as a function of $\tau_{\text {CAL-like }}$. The $T_{\text {MOD06 }}$ and $z_{\text {MOD06 }}$ are not considered here because of the too-few cases in which MOD06 detects an ice cloud using the $5 \times 5$ pixel sample. The difference between the temperatures and altitudes (Fig. 5b) generally decreases as $\tau_{\mathrm{CAL} \text {-like }}$ increases. The vertical variability is the difference between the cloud top and bottom from the CALIPSOlike method added to the standard deviation from the LaRC method.

Figure 6 shows the comparison between the optical thicknesses considering all cases, even the ones in which the LaRC and MOD06 methods do not detect any cloud, that is, when $\tau_{\mathrm{LaRC} / \mathrm{MO} 06}=0$. Figures $6 \mathrm{a}-\mathrm{c}$ show that there is good agreement among the three methods for the cases that are not too thick for the CALIPSO-like method and not too thin for the LaRC and MOD06 methods, typically meaning $\tau=0.5-3$. Nevertheless, for four thin cases, $\tau_{\text {CAL-like }}$ is smaller than $\tau_{\mathrm{LaRC}}$ and $\tau_{\text {MOD06. }}$. This result is certainly due to a collocation problem: $\tau_{\text {CAL-like }}$ is calculated using lidar and thus only for the point above the SIRTA; $\tau_{\mathrm{LaRC}}$ and $\tau_{\text {MOD06 }}$ are calculated using the strip of pixels, which could include a few pixels of a thick cloud, leading to larger values of optical thicknesses. Figure 6d shows that the difference between $\tau_{\mathrm{CAL}-\text { like }}$ and $\tau_{\mathrm{LaRC}}$ is less than 0.2 for $50 \%$ of the cases: four of these cases are cases with no detection of any cloud using the LaRC method $\left(\tau_{\mathrm{LaRC}}=0\right)$ and with $\tau_{\mathrm{CAL} \text {-like }}$ less than 0.1 ; for the four other cases, $\tau_{\mathrm{CAL}-\mathrm{like}}$ and $\tau_{\mathrm{LaRC}}$ are less than 2.5. This is almost the same for the comparison between $\tau_{\mathrm{CAL} \text {-like }}$ and $\tau_{\mathrm{MOD} 06}$, but five cases are cases with no detection of any cloud using the MOD06 method $\left(\tau_{\text {MOD06 }}=0\right)$ and with $\tau_{\text {CAL-like }}$ less than 0.15 (Fig. 6e). Nevertheless, $\tau_{\text {CAL-like }}$ is smaller than $\tau_{\text {MOD06 }}$ in $45 \%$ of the cases. There is also good agreement between $\tau_{\mathrm{LaRC}}$ and $\tau_{\text {MOD06 }}$ in $45 \%$ of the cases (difference smaller than 0.2). Overall, $\tau_{\mathrm{MOD} 06}$ tends to be larger than $\tau_{\mathrm{LaRC}}$.

Figure 7 summarizes the results for the ice particle effective radius. Figures $7-\mathrm{c}$ show that, although there is generally good agreement among the three methods, the variability of CALIPSO-like effective radius $\left(r_{e, \text { CAL-like }}\right)$ is often larger than that for either LaRC $\left(r_{e, \text { LaRC }}\right)$ or MOD06 $\left(r_{\mathrm{e}, \mathrm{MOD} 06}\right)$. The variability 

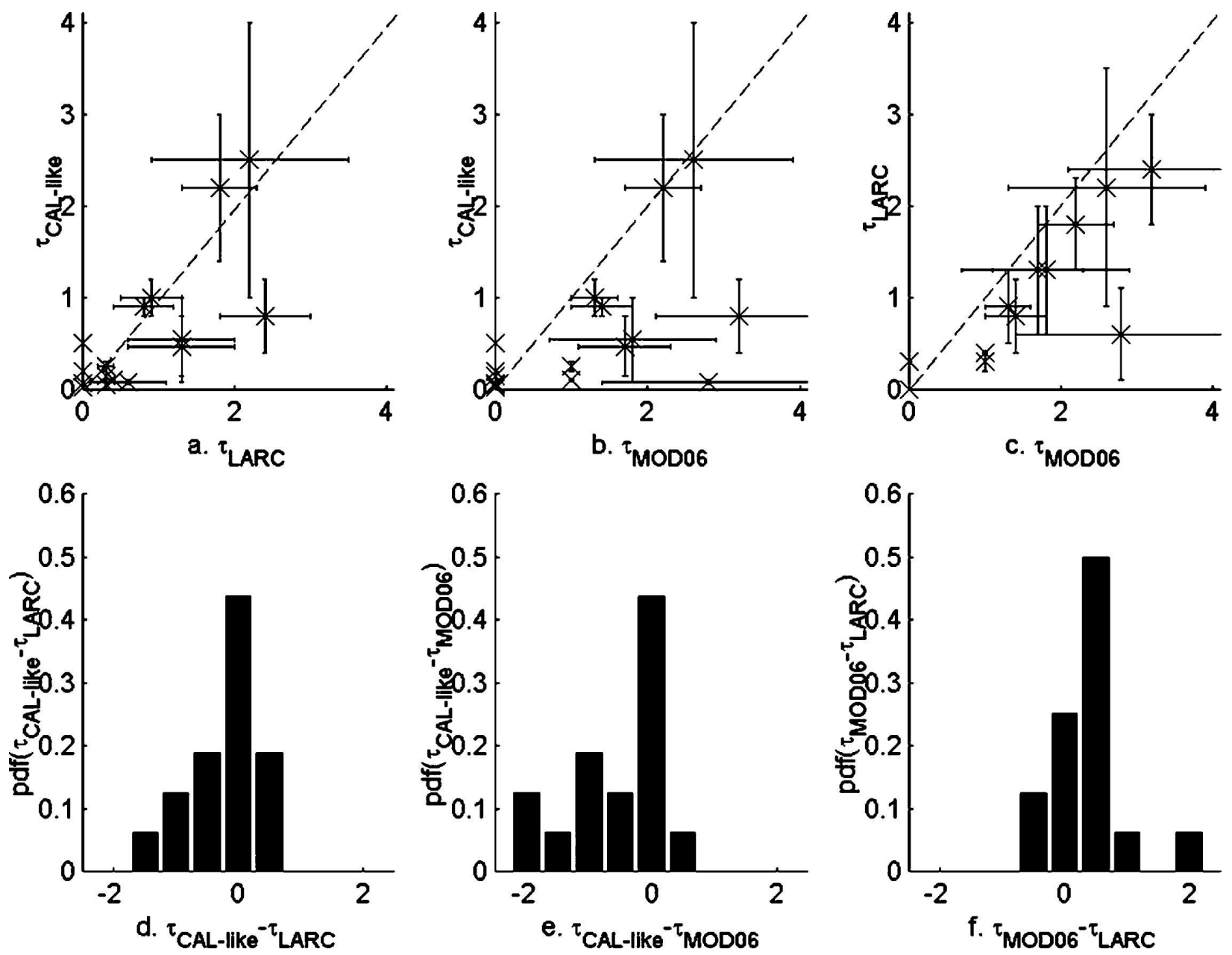

FIG. 6. SIRTA cloud cases: (a) $\tau_{\mathrm{CAL}-\text { like }}=f\left(\tau_{\mathrm{LaRC}}\right)$, (b) $\tau_{\mathrm{CAL}-\text { like }}=f\left(\tau_{\mathrm{MOD} 06}\right)$, (c) $\tau_{\mathrm{LaRC}}=f\left(\tau_{\mathrm{MOD} 06}\right)$, (d) PDF of $\tau_{\mathrm{CAL}-\mathrm{like}}-\tau_{\mathrm{LaRC}}$, (e) PDF of $\tau_{\text {CAL-like }}-\tau_{\text {MOD06 }}$, and (f) PDF of $\tau_{\text {LaRC }}-\tau_{\text {MOD06. }}$. Dashed lines are $x=y$. Error bars are standard deviation.

difference is probably a result of the differences in the microphysical models used for the retrievals (Table 1). The CALIPSO-like and LaRC methods have the best agreement: in $60 \%$ of the cases the difference between mean values of $r_{e, \text { CAL-like }}$ and $r_{e, \text { LaRC }}$ is less than $3 \mu \mathrm{m}$ (two main peaks). In $35 \%$ of the cases $r_{e, \text { CAL-like }}$ is at least $5 \mu \mathrm{m}$ larger than $r_{e, \mathrm{LaRC}}$. This difference can be very important, in particular for the 5 March 2002 case in which one can only know that $r_{e, \text { CAL-like }}$ is $14 \mu \mathrm{m}$ greater than $r_{e, \text { LaRC }}$. The comparison between $r_{e, \text { CAL-like }}$ and $r_{e, \text { MOD06 }}$ (Figs. 7b,e) is similar, but the differences are slightly greater: for $45 \%$ of the cases $r_{e, \text { CAL-like }}$ is at least $5 \mu \mathrm{m}$ smaller than $r_{e, \text { MOD06}}$. For $85 \%$ of the cases $r_{e, \mathrm{MOD} 06}$ is larger than $r_{e, \mathrm{LaRC}}$, and this difference is at least $5 \mu \mathrm{m}$ for $75 \%$ of the cases (Fig. 7c). Last, one can notice that the differences among $r_{e, \text { CAL-like }}, r_{e, \text { MOD } 06}$, and $r_{e, \mathrm{LaRC}}$ can also be due to the stratification of the cloud, because the three methods do not use the same channels (Table 1) and then do not necessarily detect exactly the same part of the cloud (Radel et al. 2003).

\section{Tropical ice clouds during CRYSTAL-FACE field experiment}

a. Observations: Instruments and dates

Ice-cloud observations collected during CRYSTALFACE in July of 2002 are used to evaluate the CALIPSO-like method in the Tropics.

\section{1) Airborne 532-NM LIDAR}

The cloud-physics lidar (CPL) is a neodymiumdoped yttrium orthovanadate (Nd:YV04) laser. It was nadir viewing on the high-altitude NASA ER-2 aircraft and measures both the backscattered signal at $532 \mathrm{~nm}$ and the linear depolarization ratio at $1064 \mathrm{~nm}$. The 

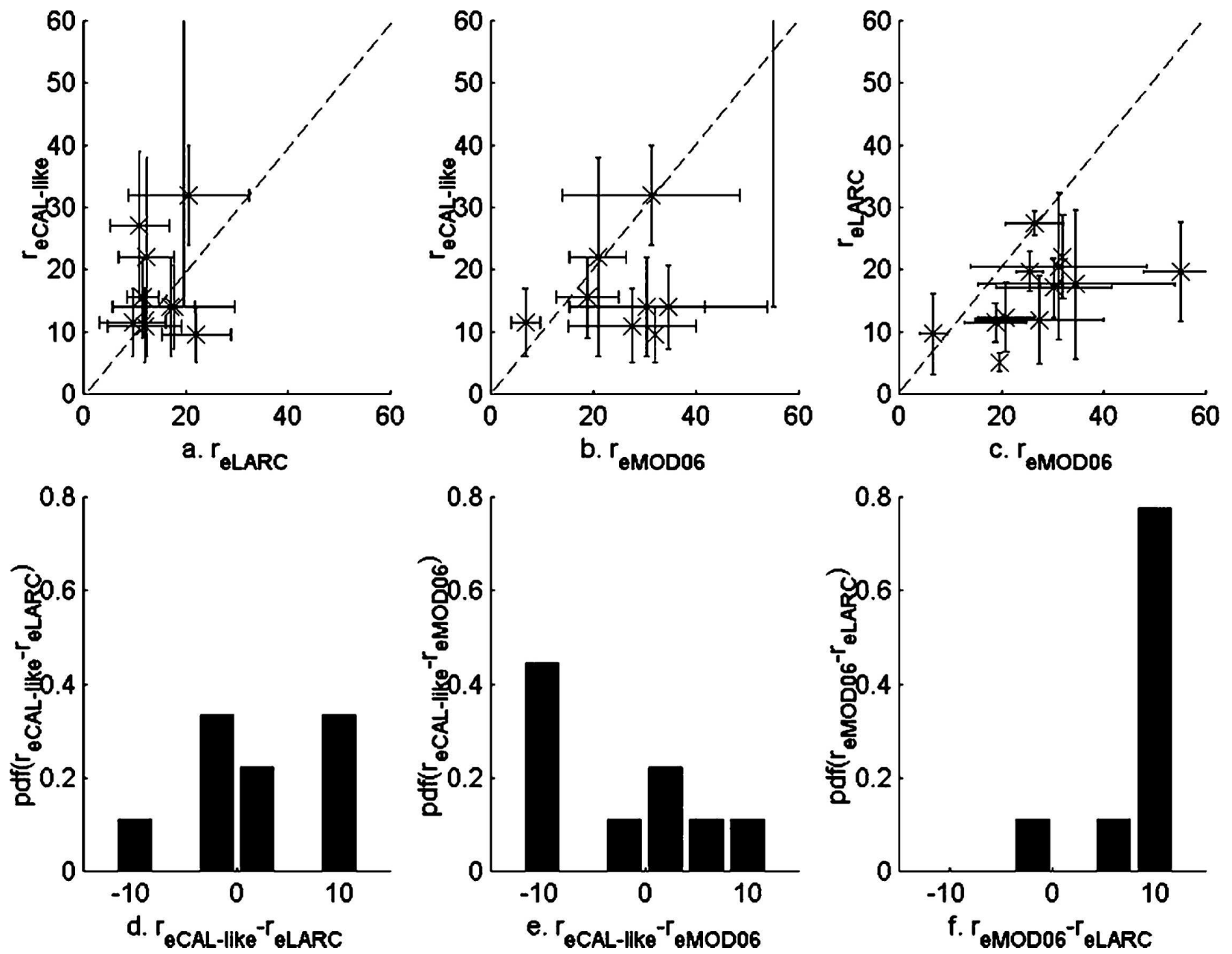

FIG. 7. SIRTA cloud cases: (a) $r_{e, \mathrm{CAL}-\text { like }}=f\left(r_{e, \mathrm{LaRC}}\right)$, (b) $r_{e, \mathrm{CAL}-\mathrm{ike}}=f\left(r_{e, \mathrm{MOD} 06}\right)$, (c) $r_{e, \mathrm{LaRC}}=f\left(r_{e, \mathrm{MOD} 06}\right)$, (d) PDF of $r_{e, \mathrm{CAL}-\mathrm{like}}-$ $r_{e, \mathrm{LaRC}}$, (e) PDF of $r_{e, \mathrm{CAL}-\text { like }}-r_{e, \mathrm{MOD} 06}$, and (f) PDF of $r_{e, \mathrm{LaRC}}-r_{e, \mathrm{MOD} 06}$. Dashed lines are $x=y$. Error bars are standard deviation.

temporal resolution is $1 \mathrm{~Hz}$, and its vertical resolution is $30 \mathrm{~m}$. For the current study, cloud-base and cloud-top altitudes and the number of cloud layers are from the CPL archived files (http://cpl.gsfc.nasa.gov/). The CPL cloud temperatures were found by comparing the cloud-base and cloud-height data with vertical profiles from the ER-2 dropsondes. The crystal shape information is based on analysis of the lidar depolarization data following the method of Noel et al. (2002).

\section{2) SAtellite-Borne IMAGer}

The 4-km GOES-8 imager provided observations every 10-15 min, enabling relatively close matches with the aircraft data. The GOES-8 data were analyzed with the LaRC method (Table 3) using hourly temperature profiles from the Rapid Update Cycle analyses. The retrieved pixel-level cloud properties were averaged for groups of the four closest pixels to a point on the ER-2 flight track.

\section{3) AN AIRBORNE SPECTROMETER}

The MAS instrument flown on the NASA ER-2 aircraft has capability that is similar to that the MODIS instrument, although with much higher spatial resolution $(50 \mathrm{~m})$ and more complete spectral coverage provided by grating spectrometers ( 50 spectral bands). The MAS data are used for both the MAS retrieval and CALIPSO-like methods using a strip of pixels that is 3 pixels $(150 \mathrm{~m})$ in the across-track direction, along the length of the selected flight leg (Table 3). The cloud properties are retrieved for each group of three pixels and then averaged together over the flight leg.

\section{4) ER-2 DROPSONDES}

These dropsondes are an automated version of the National Center for Atmospheric Research Airborne Vertical Atmospheric Profiling System (AAVAPS) produced by Vaisala, Inc., and launched from the ER-2. 
TABLE 6. Tropical ice-clouds cases during CRYSTAL-FACE.

\begin{tabular}{|c|c|c|c|c|}
\hline \multirow[b]{2}{*}{$\begin{array}{l}\text { Day (July 2002) (Start and } \\
\text { stop times, UTC) }\end{array}$} & \multirow[b]{2}{*}{$\begin{array}{l}\text { Surface temperature } \\
(\mathrm{K}),{ }^{\mathrm{a}} \text { leg No. }\end{array}$} & \multicolumn{3}{|c|}{ CALIPSO-like (MAS) } \\
\hline & & $\begin{array}{c}Z_{t}, Z_{\max }, \mathrm{b} \\
Z_{b}(\mathrm{~km})\end{array}$ & $\begin{array}{l}T_{t}, T_{\max }, \mathrm{b} \\
T_{b}(\mathrm{~K})\end{array}$ & $\begin{array}{c}\tau \mathrm{IR},{ }^{\mathrm{c}} \\
\text { shape class }\end{array}$ \\
\hline 23 18.641, 18.655) & 302,1 & $13.8,11.9,11.7$ & $209,222,223$ & $?, \mathrm{I}$ \\
\hline $23(18.858,18.870)$ & 302,2 & $13.6,11.7,11.5$ & $209,224,225$ & $?, \mathrm{I}$ \\
\hline $23(19.085,19.091)$ & 301,3 & $10.1,8.79,8.5$ & $237,247,250$ & $?, \mathrm{I}$ \\
\hline $26(18.300,18.359)$ & 303,4 & $15.4,12.5$ & 200,218 & $0.25-1, \mathrm{II}$ \\
\hline $26(18.482,18.500)$ & 303,5 & $15.4,12.5$ & 200,218 & $0.1-0.5$, I, II, III \\
\hline $26(19.000,19.079)$ & 303,6 & $15.4,12.4$ & 200,218 & $0.5-2$, I, II, III \\
\hline $28(21.575,21.578)$ & 303,7 & $14.6,13.4,13.3$ & $206,212,213$ & $?, \mathrm{II}$ \\
\hline $28(22.296,22.321)$ & 303,8 & $14.6,11.6,11.2$ & $209,226,225$ & $0.25-3$, I, II \\
\hline $28(22.945,22.973)$ & 303,9 & $14.4,13,13$ & $210,215,215$ & No data \\
\hline $29(15.702,15.710)$ & 304,10 & $11.9,10.3,10.3,+5.7-6$ & $222,233,233,+263$ & $0.5-10, \mathrm{I}$ \\
\hline $29(15.811,15.823)$ & 304,11 & $11.9,10.5,+5-5.5$ & $222,231,+267$ & $>2, \mathrm{I}$ \\
\hline $29(19.814,19.827)$ & 304,12 & $13.5,13.1,12.5$ & $215,218,221$ & $?, \mathrm{I}$ \\
\hline $29(20.300,20.322)$ & 304,13 & $13.5,12.5,12.5$ & $215,221,221$ & $2-10$, I, II, III \\
\hline $29(20.424,20.440)$ & 304,14 & $13.5,12.5,12.5$ & $215,221,221$ & 1-10, I, II, IIII \\
\hline
\end{tabular}

a Temperature of dropsonde lowest layer.

${ }^{\mathrm{b}}$ Altitude and temperature of maximum lidar backscattered signal (altitude taken into account in the radiative transfer calculation for the CALIPSO-like method).

${ }^{\mathrm{c}}$ For the CALIPSO-like method, optical thickness is from the radiative transfer calculation instead of the observation because clouds are often too thick to retrieve the optical thickness directly from the lidar. This is infrared optical thickness.

Details pertaining to the AAVAPS characteristics and performance are described in Hock and Franklin (1999). From an ejection altitude of $24 \mathrm{~km}$, the dropsonde requires about $22 \mathrm{~min}$ to descend to the ocean surface. Between five and six dropsondes were released during each ER-2 flight. Dropsondes are not available for the 29 July flight; hence, for this day, data taken by the Balloon-Borne Sounding System launched from the Key West, Florida, ground station $\left(25^{\circ} \mathrm{N}, 81^{\circ} \mathrm{W}\right)$ were used.

\section{5) IN SITU MEASUREMENTS}

Measurements of the hydrometeor size spectra were made with three instruments-the Cloud, Aerosols, and Precipitation Spectrometer (CAPS), Cloud Particle Imager (CPI), and SPP-100 optical spectrometer on the WB-57. The CAPS measures particle diameter over two ranges, 0.5-44 and 75-1600 $\mu \mathrm{m}$ (Baumgardner et al. 2001), the SPP-100 measures between 4 and $47 \mu \mathrm{m}$, and the CPI covers 10-300 $\mu \mathrm{m}$. To generate size spectra over the size range from 0.5 to $1600 \mu \mathrm{m}$, a composite was created by concatenating the measurements and calculating average concentrations in the overlapping sizes. The particle volumes and cross-sectional areas were computed from the size distributions with an assumption that the particles were quasi spherical with density 0.9. Recent studies (Baumgardner et al. 2005) show that the cirrus particles in CRYSTAL-FACE had shapes that are representative of ensembles of bullet rosettes, plates, and hollow columns, all with equivalent volumes somewhat less than a sphere. The volumes could be overestimated by as much as $50 \%$ based on comparisons of different habits with equivalent spheres, and the area could be overestimated by as much $30 \%$. An additional error of $\pm 30 \%$ and $\pm 20 \%$ in volume and area is estimated as due to instrument limitations. These limitations are related to the uncertainty in optical sample volume, electronic response time, and digitization errors (Baumgardner et al. 2001). The estimated root-sum errors for volume and area are from $-30 \%$ to $+58 \%$ and from $-20 \%$ to $+36 \%$, respectively. The uncertainties in volume and area are correlated; hence, error propagated into the calculation of effective radius goes approximately from $-36 \%$ to $+68 \%$.

Collocated ER-2 and WB-57 aircraft data were determined using navigational recorder data provided by K. Drdla (which was also available online at http:// 
TABLE 6. (Extended)

\begin{tabular}{|c|c|c|c|c|c|}
\hline \multicolumn{3}{|c|}{ LaRC (GOES) } & \multicolumn{2}{|c|}{ MAS (MAS) } & \multirow[b]{2}{*}{ Comments } \\
\hline $\begin{array}{l}T_{e}(\mathrm{~K}), \mathrm{GOES} \\
\text { time (UTC) }\end{array}$ & $\begin{array}{l}Z_{t}, Z \text { range } \\
Z_{b}(\mathrm{~km})\end{array}$ & $\tau, Z$ range & $\begin{array}{c}Z_{t} \\
(\mathrm{~km})\end{array}$ & $\tau$ & \\
\hline $224,18.42$ & $11.7,11-12,6.8$ & $27.9,14-35$ & 12.2 & $0-35$ & Thick cloud, LaRC: ice, MAS: ice \\
\hline $225,18.42$ & $11.6,11.3-12,7.0$ & $18.9,11-22$ & 12.2 & $6-8$ & Thick cloud, LaRC: ice, MAS: ice \\
\hline $250,18.92$ & $8.3,8.3,4.9$ & $16.9,16.9$ & 10.9 & $5-10$ & Thick cloud, LaRC: ice, MAS: ice \\
\hline $259,17.9$ & $7.5,5-10,7$ & $0.87,0.7-1$ & 10.9 & $0-9$ & $\begin{array}{l}\text { Thin ice cloud, possible low layer, LaRC: water }+ \text { ice, } \\
\text { MAS: multi ice }\end{array}$ \\
\hline $232,18.75$ & $11.7,9-15.7,10.4$ & $0.87,0.5-1.4$ & 10.9 & $0-17$ & $\begin{array}{l}\text { Thin ice cloud, possible low layer, LaRC: ice, MAS: } \\
\text { multilayer ice+water+clear }\end{array}$ \\
\hline $254,18.75$ & $8.7,6-13,7.7$ & $1.3,0.5-2$ & 10.9 & $0-8$ & $\begin{array}{l}\text { Thin ice cloud, LaRC: ice, MAS: single-layer ice + } \\
\text { multiplayer mixed }\end{array}$ \\
\hline $216,21.59$ & $12.8,12.8,6.7$ & $68,57-71$ & 14.5 & $5-48$ & Thick cloud, LaRC: ice, MAS: ice \\
\hline $260,22.32$ & $9.8,8.5,5-12.7$ & $1.3,0.5-1.9$ & 10.8 & $1-3$ & Possible low layer, LaRC: water/ice, MAS: ice \\
\hline $220,22.99$ & $12.4,11-13,7.7$ & $21,5,7-44$ & 13.5 & $1-46$ & Missing MAS data, LaRC: ice, MAS: ice \\
\hline $260,15.67$ & $7.7,7.2-7.8,6.6$ & $2.9,2-5$ & 10.7 & $4-45$ & $\begin{array}{l}\text { CALIPSO-like: + low layer, LaRC: ice, MAS: single } \\
\text { ice + multilayer mixed }\end{array}$ \\
\hline $261,15.75$ & $7.6,7.6,6.3$ & $3.9,3.9$ & 10.7 & $2-6$ & $\begin{array}{l}\text { CALIPSO-like: + low layer ambiguous phase, LaRC: } \\
\text { water, MAS: water }\end{array}$ \\
\hline $219,19.75$ & $12.5,12.5,6$ & 128,128 & 14.5 & $20-62$ & Thick anvil, LaRC: ice, MAS: ice \\
\hline $250,20.25$ & $9.5,6-12,7.8$ & $2.5,1-3$ & 10.7 & $3-5$ & $\begin{array}{l}\text { Thick anvil, no CALIPSO-like model match, LaRC: } \\
\text { ice, MAS: ice }\end{array}$ \\
\hline $248,20.25$ & $9.9,7-11,8.1$ & $2.3,1-4$ & 10.7 & $2-5$ & $\begin{array}{l}\text { Thick anvil, no CALIPSO-like model match, LaRC: } \\
\text { ice, MAS: ice }\end{array}$ \\
\hline
\end{tabular}

www.espoarchive.nasa.gov/cgi-bin/dl_start). The ER-2 and WB-57 data are considered to be coincident when the planes pass the same location $\pm 1 \mathrm{~km}$ within $\pm 20 \mathrm{~min}$.

The cases were selected using almost the same criteria as in midlatitudes (section 3b). The main difference is that for CRYSTAL-FACE each case corresponds to a flight leg instead of a day, and several flight legs are studied in a given day. Using the CPL information, a flight leg is selected for which the cloud has relatively constant $( \pm 150 \mathrm{~m})$ bottom and top altitudes so that a single IR radiative transfer computation can be used for the entire flight leg to apply the CALIPSO-like method. The lidar depolarization is used to select ice cloud in flight legs. For those cases, the CALIPSO-like method is not limited to cases in which $\tau<3$ because both the imager (MAS or GOES) and lidar (CPL) are down viewing. Nevertheless, other limitations of this method will be demonstrated. Fourteen different flight legs are analyzed. Particle effective radii and optical thickness are retrieved for each pixel and then averaged along the flight leg. Table 6 summarizes the dates and time periods of observations for the different instruments and the altitudes of each cloud.

\section{b. Comparison of the three methods}

\section{1) Illustrative CASE: Flight LeG 8}

Figure 8 a shows the temporal and altitude variation of the CPL lidar depolarization ratio. It indicates that the cloud-top altitude varies between 15 and $11 \mathrm{~km}$. Around 2217 UTC (red arrow), the cloud-top altitude is constant and the depolarization ratio ranges between $30 \%$ and $50 \%$ within the cloud, indicating that it is an ice cloud. Figure $8 \mathrm{~b}$ shows the GOES visible image at this time together with the ER-2 plane flight track. The rise in the cloud top around 2211 UTC is evident as a shadow line in the visible image. At 2217 UTC, the ER-2 is over the ocean, making this flight leg a good case study because the surface albedo is known. Figure $8 \mathrm{~b}$ shows that the plane crosses the edge of a cumulonimbus anvil at the end of the flight leg (blue and magenta line segments). For this flight leg, the LaRC method classified most of the pixels as ice except for a few pixels that were defined as liquid water or clear. The MAS and CALIPSO-like techniques classified all of the pixels as ice clouds. This difference is likely due to the large discrepancies in spatial resolutions between the LaRC method using GOES data $(8-\mathrm{km}$ resolution across and 4-km resolution along the flight leg) and CALIPSO-like and MAS methods using MAS data (150-m resolution along the flight leg). The patterns in optical thickness seen in the MAS (Fig. 6c) and GOES (Fig. 6d) results are generally consistent over the relatively short length of the flight leg. The ice-cloud optical thickness is often larger than 3 in anvils; hence, for the CALIPSO-like method, the cloud optical thickness is determined in the IR by comparing the radiative transfer computations with the measured radiance (Table 1). 

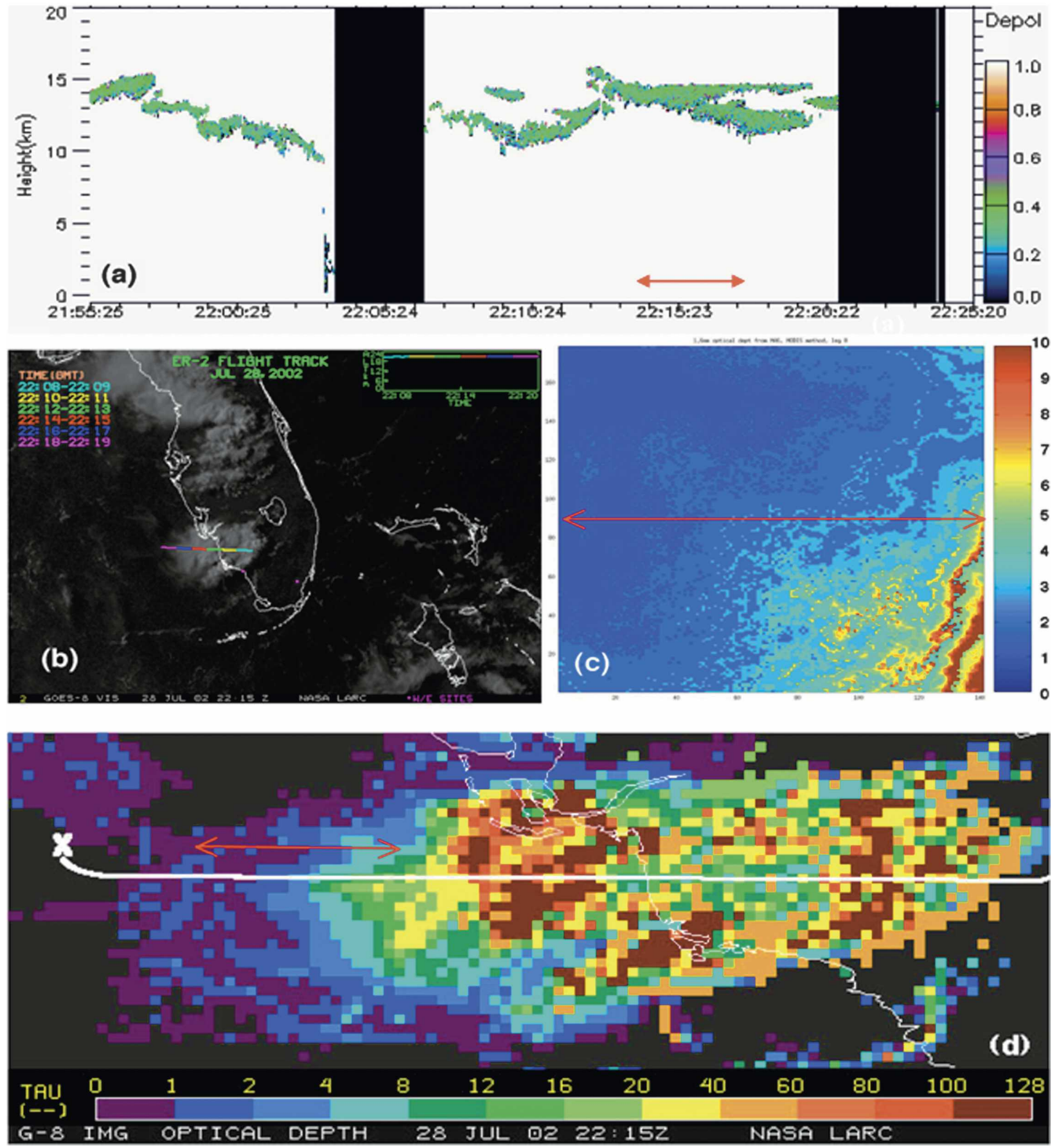

FIG. 8. The 28 Jul flight leg from 2217:47 to 2219:17 UTC: (a) CPL depolarization ratio, (b) GOES visible image, (c) optical thickness retrieved from MAS data using the MAS method, and (d) optical thickness derived from GOES-8 using the LaRC method. Red arrow is the considered flight leg.

Table 7 summarizes the results obtained with the three methods for flight leg 8. Both passive remote sensing techniques underestimate the cloud altitude as detected by the lidar: the LaRC method locates the cloud between $4.5 \mathrm{~km}$ below the cloud base and $0.5 \mathrm{~km}$ above cloud base, whereas the MAS method identifies it as just below the cloud base. The lidar does not actually detect the real cloud base, whereas the passive remote sensing derives a cloud altitude corresponding to somewhere within the cloud, depending on the icecloud composition and the sensitivity of the channels to absorption and diffusion phenomena used in the pas- 
TABLE 7. Results of the three retrieval methods for flight leg 8; mean with range in parentheses.

\begin{tabular}{lcccr}
\hline \hline Method & Altitude $(\mathrm{km})$ & Temperature $(\mathrm{K})$ & Optical thickness & Particle effective radius $(\mu \mathrm{m})$ \\
\hline CALIPSO like & $11.2-14.6$ & $209-225$ & $0.25-3.0$ & $27(22-32)$ \\
LaRC & $5.3-12.7$ & $234-268$ & $0.5-1.9$ & $31(22-40)$ \\
MAS & 10.8 (top) & - & $1-3$ & $34.5(31-38)$ \\
\hline
\end{tabular}

sive remote sensing technique. In a similar way, $T_{\mathrm{LaRC}}$ is $\sim 27 \mathrm{~K}$ greater than $T_{\text {CAL-like }}$ Hence, both passive methods miss the highest part of the cloud, whereas the CALIPSO-like method misses the lower part of the cloud where the lidar cannot penetrate. This result is consistent with the analysis of Sherwood et al. (2004) who found that the thermal infrared GOES channel brightness temperatures correspond to an altitude 1-2 $\mathrm{km}$ below the physical top of even the densest cumulonimbus clouds.

In general, there is a good agreement between the CALIPSO-like method and both passive methods for the optical thicknesses. The three methods yield mean particle effective radii ranging between 22 and $40 \mu \mathrm{m}$ with variability between 7 and $18 \mu \mathrm{m}$, depending on the method. The CALIPSO-like method yields the smallest mean value of $r_{e}(27 \mu \mathrm{m})$.

\section{2) All 14 CRYSTAL-FACE FLight LEGS}

Table 6 summarizes the results for 14 CRYSTALFACE flight legs. LaRC results are reported only for the pixels identified as ice clouds. For five flight legs (all three 23 July flight legs, flight leg 7, and flight leg 12) no particle effective radius and optical thickness were retrieved using the CALIPSO-like method because the measured BTD values were outside the range of the model calculations (hypothesis of calibration error have been removed after a clear-sky validation-not shown). Those five flight legs correspond to very large values of $\tau_{\text {LaRC }}$ and $\tau_{\text {MAS }}$ (Table 6 ), with a maximum value of $\tau_{\text {LaRC }}$ equal to 127 (flight leg 12). For such thick clouds, the BTDs measured by MAS in the CALIPSO-like channels have values ranging between -1 and $-3.5 \mathrm{~K}$ (depending on the spectral interval). Such values cannot be reproduced by simulations, whatever the microphysical properties of the crystals. All of those cases correspond to large convective systems as seen in the GOES visible images (not shown) with optical depth larger than 11 as retrieved by LaRC method (Table 5). Hence, the CALIPSO-like method cannot be applied for this kind of clouds because of their microphysical properties. During four of the five flight legs, the lidar depolarization is very low, indicating that the cloud particles could be spherical or aspect ratio of class I (i.e., plates). This class was found in seven other flight legs.

For two cases (flight legs 13 and 14) that also corre- spond to very thick clouds, the CALIPSO-like method was applied to pairs of channels to select a particle model for each BTD, but none of the particle models could explain consistently the three different BTD values; hence, the particle effective radius could not be retrieved. This is probably because the cloud particles in those flight legs are not represented in any of the CALIPSO-like particle models. Infrared and visible optical properties computation are not yet available for such crystals but will be available for the operational version of this method, that is, for applying it to the CALIPSO instruments. For the eight cases in which $r_{e, \mathrm{CAL}-\text { like }}$ could not be retrieved, however, both passive methods produced results. As seen in Fig. 9, $r_{e, \text { MAS }}$ greatly exceeds its LaRC counterpart for four of those cases, and results from the two methods agree within $\pm 1 \mu \mathrm{m}$ for the other four cases.

Results from the three different methods are compared in Figs. 10-12 for the other seven flight legs. Figure $10 \mathrm{a}$ plots $T_{\mathrm{CAL}-\mathrm{like}}$ as a function of $T_{\mathrm{LaRC}}$. Variability is the difference between the cloud top and bottom detected with CPL, whereas the LaRC one is a standard deviation of the cloud effective temperature, calculated in the box of pixels used for the retrieval. Figure $10 \mathrm{~b}$ shows the PDF of the difference between $T_{\mathrm{CAL} \text {-like }}$ at the cloud-middle height and the mean $T_{\text {LaRC }}$. Except for one case, $T_{\text {CAL-like }}$ is always less than $T_{\mathrm{LaRC}}$. As for flight leg 8 (previous section), the LaRC method often misses the highest (coldest) part of the cloud (cooler) whereas the CALIPSO-like method often misses the lowest (warmest) part of the cloud. Exceptions include the two cases in which the lidar detected a midlevel cloud below the cirrus cloud. In those two cases, the optical thickness of the upper cloud was so small that the LaRC technique only detected the lower cloud because $T_{\text {LaRC }}$ and the low-cloud temperature from the CALIPSO-like method are nearly identical (not shown). In $45 \%$ of cases the difference between $T_{\text {CAL-like }}$ and $T_{\text {LaRC }}$ is smaller than $10 \mathrm{~K}$. This tendency is confirmed in Figs. 10c and 10d, which compare the cloud altitudes retrieved from all three methods. In $92 \%$ of cases $z_{\text {CAL-like }}$ is higher than $z_{\text {LaRC }}$, and in one case in which the lidar detected two layers the difference is $7 \mathrm{~km}$. The difference between $z_{\text {CAL-like }}$ and $z_{\text {MAS }}$ is smaller: $z_{\text {CAL-like }}$ is larger than $z_{\text {MAS }}$ in only $43 \%$ of the cases. Otherwise, $z_{\text {MAs }}$ is higher than $z_{\text {LaRC }}$ all of 


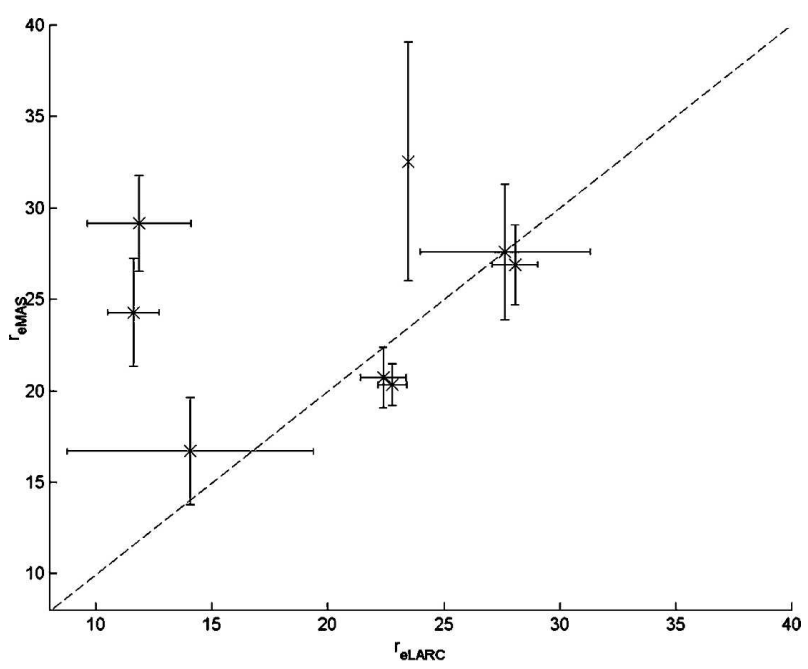

FIG. 9. CRYSTAL-FACE cases for which CALIPSO-like retrieval is not possible: $r_{e, \mathrm{MAS}}=f\left(r_{e, \mathrm{LaRC}}\right)$. Dashed line is $x=y$. Error bars are standard deviation.

the time, and the difference is larger than $6 \mathrm{~km}$ in $45 \%$ of cases. For the thin clouds, for example, the three flight legs of 26 July 2002, the lidar can detect even the thinnest parts of the cloud, as indicated by the range of retrieved optical thicknesses. As seen for the SIRTA cases, the range of optical thicknesses retrieved by MAS and LaRC tends to be bounded by a greater minimum value than found by the CALIPSO-like approach and the passive method cloud heights are, on the whole, less than the lidar-determined values (Fig. 10c).

Figure 11 compares the optical thicknesses obtained with the three methods. The difference between $\tau_{\text {MAS }}$ and $\tau_{\text {LaRC }}$ is less than 1 for only $12 \%$ of cases, and $\tau_{\text {MAS }}$ is larger than $\tau_{\mathrm{LaRC}}$ by more than 2 for $50 \%$ of cases. As shown in Table 6, this difference is very large for the flight legs without CALIPSO-like retrievals. The CALIPSO-like optical thickness cannot be retrieved from the same technique as for SIRTA cases because CRYSTAL-FACE clouds are very thick and therefore the lidar does not detect the cloud bottom and it is not possible to calculate any lidar optical thickness. Hence, we use the infrared radiances to estimate an infrared optical thickness that is called $\tau \mathrm{IR}_{\text {CAL-like. }}$. It cannot be compared directly with the other methods because it is an infrared optical thickness, whereas $\tau_{\text {MAS }}$ and $\tau_{\text {LaRC }}$ are visible optical thickness. When considering a cloud composed of large nonspherical particles, the ratio between visible and infrared optical thicknesses is about 2 . Figures $11 \mathrm{a}$ and $11 \mathrm{~b}$ show that the plot of $\tau \mathrm{IR}_{\mathrm{CAL} \text {-like }}$ as a function of $\tau_{\mathrm{MAS}}$ and $\tau_{\mathrm{LaRC}}$ is better matched with the $x=2 y$ line than with the $x=y$ line, especially for the smallest optical thickness values. Because the CALIPSO-like optical thicknesses for the CRYSTAL-
FACE data are based on infrared retrievals, any values exceeding 3 or 4 are highly suspect. The MAS retrieval tends to yield greater optical thicknesses than the LaRC approach.

Figure 12 shows the comparisons between the particle effective radii obtained with the three methods. In only one of those cases in which the three retrieval methods can be applied, the effective radius retrievals from the three methods are in agreement (Figs. 12a,b). For the other cases, the mean CALIPSO-like retrieval can be 2 times the LaRC and MAS values. The agreement between the CALIPSO-like and LaRC results is slightly better than that with the MAS method. On average, for the five cases $r_{e, \text { CAL-like }}$ is $20.5 \mu \mathrm{m}$, as compared with 11 and $13.5 \mu \mathrm{m}$ for LaRC and MAS, respectively. The differences in $r_{e}$ for the two passive methods in Fig. 12c (37\%) are much like those seen in Fig. 9 $(33 \%)$. Table 6 shows that for those five flight legs, the lidar depolarization ratios lead to aspect ratios $Q$ in classes I, II, and III; that is, $Q<1.1$. With this knowledge, it is difficult to trust the $r_{e \text {,LaRC }}$ retrieval because it only uses column habits (Table 1 ), corresponding to $Q>1.1$. This fact could explain the large difference between $r_{e, \mathrm{CAL}-\text { like }}$ and $r_{e, \mathrm{LaRC}}$ or $r_{e, \mathrm{MAS}}$ (more than 8 $\mu \mathrm{m}$ for $65 \%$ of the cases).

\section{c. Comparison with in situ measurements}

The particle effective radius results are compared with in situ measurements in Table 8. For the sake of sampling, the WB-57 aircraft is considered to be collocated with the ER-2 if the time difference between the passages of two aircraft over the coincident point (defined in section 4a) is less than $22 \mathrm{~min}$, even if this time difference could correspond to a large spatial difference: for example, if the horizontal wind speed is about $20 \mathrm{~m} \mathrm{~s}^{-1}, 22 \mathrm{~min}$ will correspond to a $26-\mathrm{km}$ spatial difference. Hence, five flight legs have the WB-57 passing over coincidence points to within 14-22 min of the ER-2 flight path. For example, flight leg 12 is at 19.82 UTC for ER-2, and the coincident point for WB-57 is $14 \mathrm{~min}$ later, that is, at $20.05 \mathrm{UTC}$; hence, the averaged value and the standard deviation of $r_{e, \text { in situ }}$ (Table 8) is estimated using values between 19.97 and 20.13 UTC, that is, 10 min around the coincident point. A value of $r_{e, \text { in situ }}$ is estimated at each time by calculating $\langle V\rangle$ and $\langle A\rangle$ for the all-size distribution, from 0.175 to $800 \mu \mathrm{m}$, and using (3). Tests have been done (not shown) by considering the size distribution only from 1.5 to 800 $\mu \mathrm{m}$ to know if small particles introduce a bias in the results: it only changes the results by $0.5 \mu \mathrm{m}$ at the most. Furthermore, we explained in section 4a that the habit hypothesis for in situ leads to a $\pm 40 \%$ error on the $r_{e, \text { in situ }}$ calculation. The value of this uncertainty is 

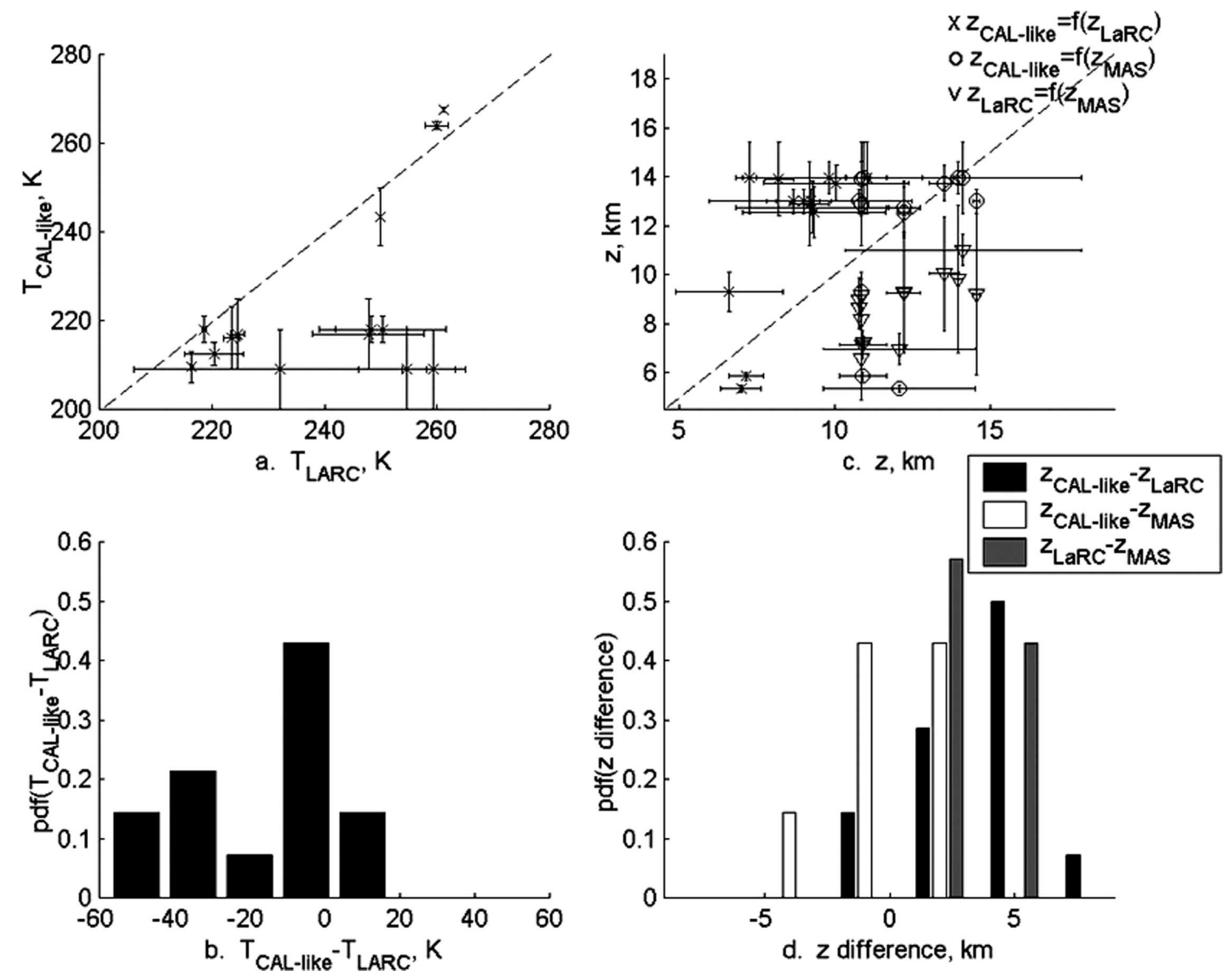

FIG. 10. CRYSTAL-FACE cloud cases: (a) $T_{\text {CAL-like }}=f\left(T_{\text {LaRC }}\right)$, (b) PDF of $T_{\text {CAL-like }}-T_{\text {LaRC }}$, (c) $z_{\text {CAL-like }}=f\left(z_{\text {LaRC }}\right)$ (times signs), $z_{\mathrm{CAL}-\text { like }}=f\left(z_{\mathrm{MAS}}\right)$ (open circles), and $z_{\mathrm{LaRC}}=f\left(z_{\mathrm{MAS}}\right)$ (upside-down triangles), and (d) PDF of $z_{\mathrm{CAL}-\text { like }}-z_{\mathrm{LaRC}}$ (black), PDF of $z_{\mathrm{CAL}-\text { like }}-z_{\mathrm{MAS}}$ (white), and PDF of $z_{\mathrm{LaRC}}-z_{\mathrm{MAS}}$ (gray). Dashed lines in (a) and (c) are $x=y$.

also presented in Table 8. Only one of those five flight legs corresponds to a case with a possible CALIPSOlike retrieval. For this flight leg 8 , as noted earlier, the agreement is good between CALIPSO-like, LaRC, and MAS retrievals, and the table shows that it is also in a good agreement with in situ measurements. Nevertheless, the uncertainty about $r_{e, \text { in situ }}$ shows that its value can be from 20 to almost $50 \mu \mathrm{m}$, a large range. Also, the remote observations give a mean effective radius weighted over the vertical extent of the cloud, whereas the in situ observations are collected at a given altitude of the cloud. Moreover, the coincidence time for this flight leg is $22 \mathrm{~min}$, the greatest for the set, and that could lead to collocation problems. For other cases (Table 8), the in situ particle sizes are still in very good agreement with the other-in particular, with the MAS method. They still have a larger range because of the uncertainty, and for legs 12,13, and 14, they tend to be larger than the LaRC ones.

\section{Discussion and conclusions}

This study intends to compare ice-cloud properties derived from the so-called CALIPSO-like method using collocated passive and active remote sensing observations with two other well-known passive imager methods (from the CERES team and the MODIS operational cloud product team). The CALIPSO-like method requires lidar measurements and is most suitable for thin ice clouds. Nevertheless, this method must be validated in different ice-cloud conditions (thin and thick) and at different latitudes (midlatitudes at SIRTA and Tropics in Florida). Figure 13 shows the phase retrieval from the two passive remote sensing methods when the lidar algorithm detects an ice cloud (i.e., for 

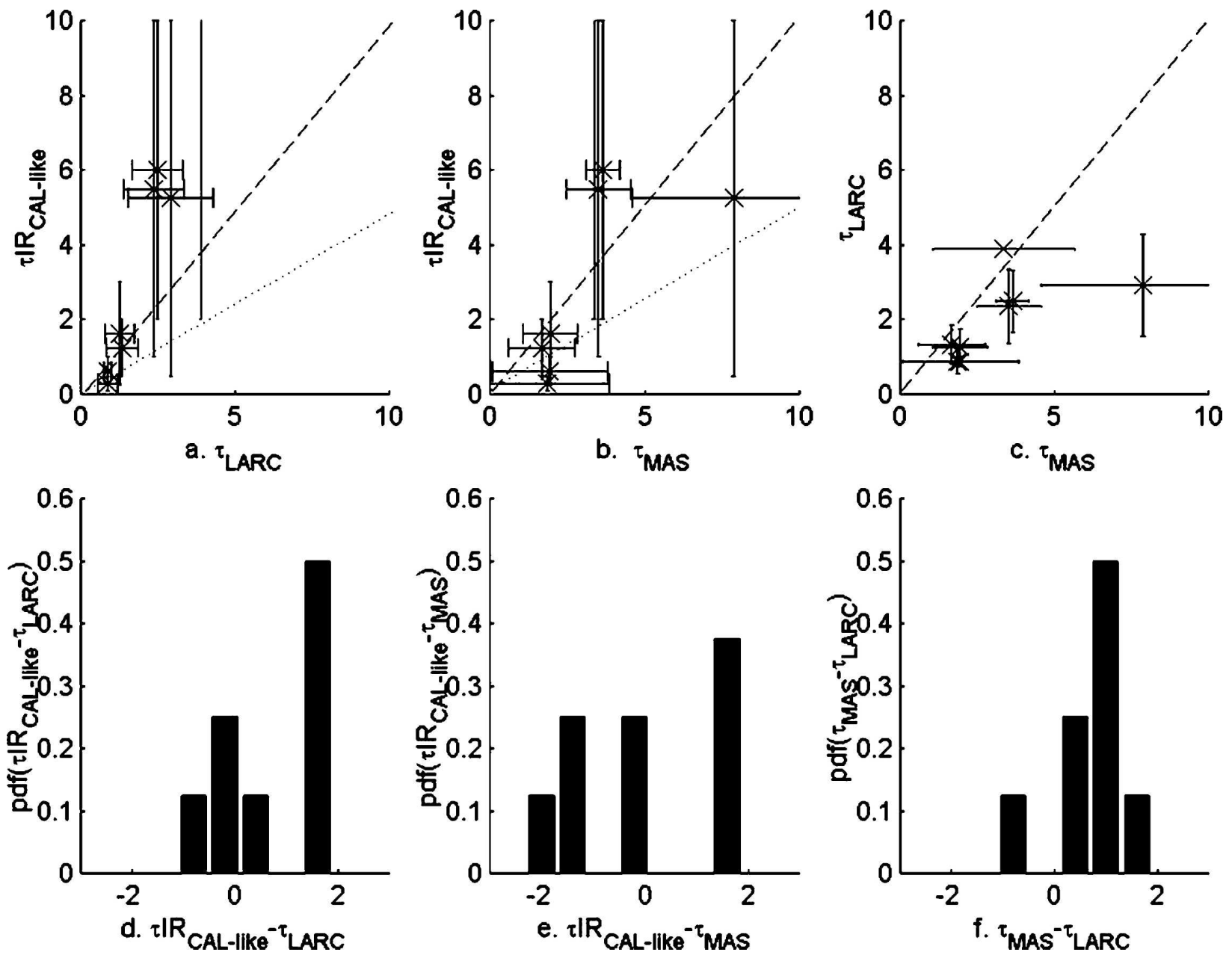

FIG. 11. CRYSTAL-FACE cloud cases: (a) $\tau \mathrm{IR}_{\text {CAL-like }}=f\left(\tau_{\text {LaRC }}\right)$, (b) $\tau \operatorname{IR}_{\text {CAL-like }}=f\left(\tau_{\text {MAS }}\right)$, (c) $\tau_{\text {LaRC }}=f\left(\tau_{\text {MAS }}\right)$, (d) PDF of $\tau \mathrm{IR}_{\mathrm{CAL}-l i k e}-\tau_{\mathrm{LaRC}}$, (e) PDF of $\tau \mathrm{IR}_{\mathrm{CAL}-\text { like }}-\tau_{\mathrm{MAS}}$, and (f) PDF of $\tau_{\mathrm{LaRC}}-\tau_{\mathrm{MAS}}$. Dashed lines are $x=y$, and dotted lines are $x=$ $2 y$. Error bars are standard deviation.

all the selected cases). The "liquid water + ice" occurrence means that liquid water and ice are found in the sample of pixels and not that there is mixed phase. There is actually no mixed-phase category for LaRC and MOD06/MAS retrievals. The agreement among the three methods concerning the detection of ice is better for tropical ice clouds: $70 \%$ of tropical clouds are ice for the LaRC method as compared with $50 \%$ for midlatitude clouds, and $84 \%$ of tropical clouds are ice for the MOD06/MAS method as compared with $45 \%$ for midlatitude clouds. For tropical clouds, $30 \%$ are interpreted as ice and water by the LaRC algorithms as compared with $8 \%$ by the MOD06/MAS algorithm. Furthermore, for midlatitude cases, $35 \%$ for LaRC algorithms and $30 \%$ for MOD06/MAS are classified as clear sky. There is no case interpreted as only water by the LaRC algorithms, whereas $5 \%$ at midlatitude and $8 \%$ at Tropics are only water for MOD06/MAS. Some of the phase misclassifications for the LaRC retrievals in the midlatitudes result from using the $1.6-/ 0.65-\mu \mathrm{m}$ reflectance ratio in the phase decision for the MODIS Terra data. Recent comparisons with LaRC MODIS Aqua retrievals, which did not use the ratio, indicate that, over land, the ratio was not properly selected for thin cirrus clouds so that the LaRC method misclassified ice pixels as water more often than without the ratio. Future editions of the LaRC phase algorithm will eliminate the ratio in phase decisions. The differences between the MAS and GOES phase decisions in the tropical cases are more likely due to the pixel size differences than any other factor because the 4-km pixels from GOES are more likely to be contaminated by small cumulus clouds than are the 50-m MAS pixels.

Overall, these results confirm the importance of lidar observations for thin ice-cloud retrievals. The CALIPSO-like technique is then well suited for this 

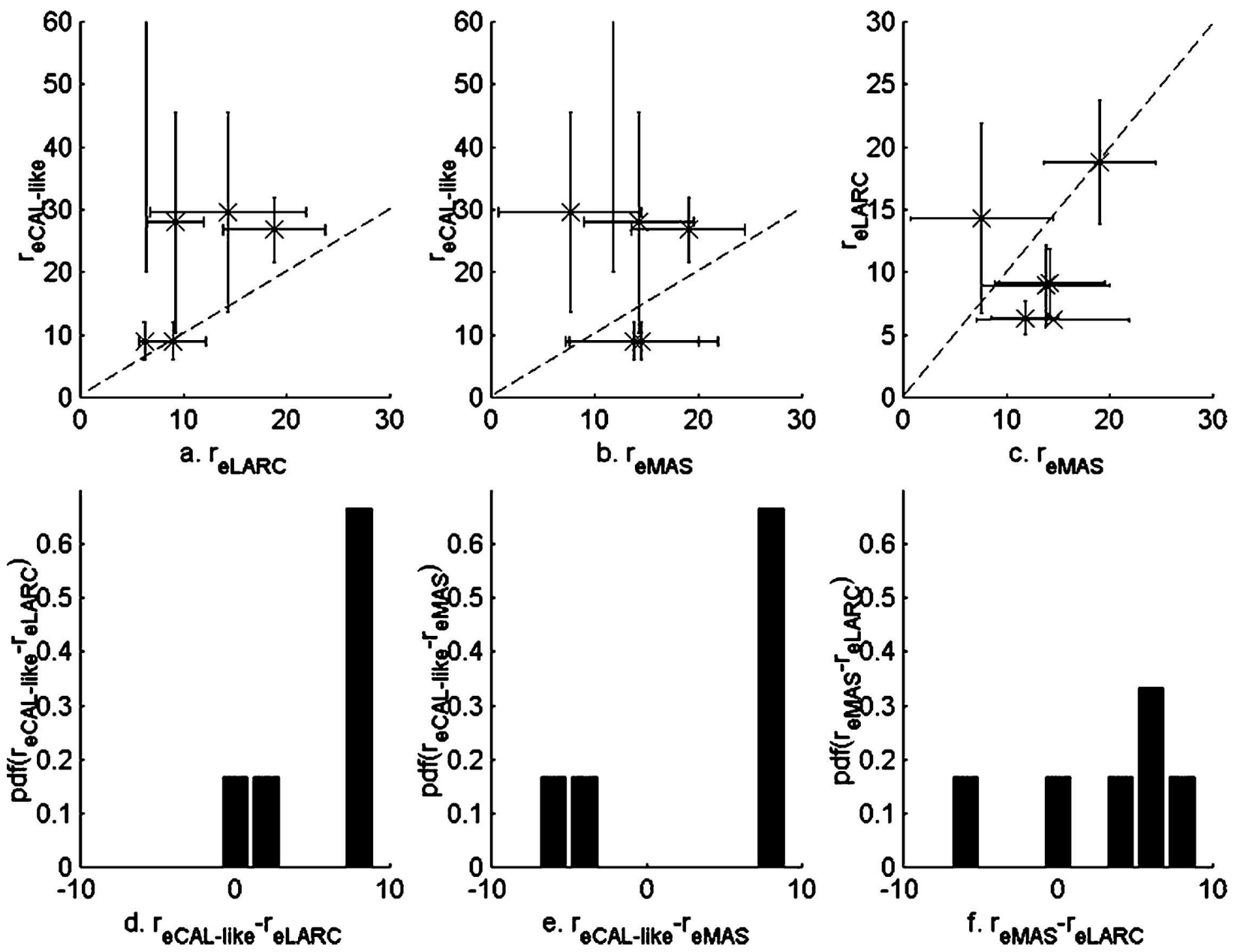

FIG. 12. CRYSTAL-FACE cloud cases: (a) $r_{e, \text { CAL-like }}=f\left(r_{e, \text { LaRC }}\right),\left(\right.$ b) $r_{e, \text { CAL-like }}=f\left(r_{e, \text { MAS }}\right)$, (c) $r_{e, \text { LaRC }}=f\left(r_{e, \text { MAS }}\right)$, (d) PDF of $r_{e, \mathrm{CAL}-\mathrm{like}}-r_{e, \mathrm{LaRC}}$, (e) PDF of $r_{e, \mathrm{CAL}-\text { like }}-r_{e, \mathrm{MAS}}$, and (f) PDF of $r_{e, \mathrm{LaRC}}-r_{e, \mathrm{MAs}}$. Dashed lines are $x=y$. Error bars are standard deviation.

kind of cloud, despite its sensitivity to small changes or uncertainties in the brightness temperature of each IR channel used, in particular, because of the surface emissivity or the calibration (Chiriaco et al. 2004).

In addition to differences in resolution or phase selection methods, the LaRC, MOD06/MAS, and CALIPSO-like methods are expected to yield discrepancies in retrieved properties. It is obvious that the lidar-derived heights correspond to physical boundaries whereas the LaRC and MOD06/MAS heights corre- spond to effective radiating heights. The MOD06 approach is based on the $\mathrm{CO}_{2}$-slicing technique, which determines the cloud pressure directly from the $\mathrm{CO}_{2}$ infrared channels. The LaRC method first retrieves $\tau$ from the visible reflectance and then assumes a certain relationship between the infrared emissivity and $\tau$. If $\tau$ is too large, then the emissivity will be too great and the height will be too low. The value of $\tau$ derived from the MOD06 analysis is independent of the $\mathrm{CO}_{2}$-derived height. Thus, the MOD06 optical depth can overesti-

TABLE 8. Comparison among $r_{e, \text { in situ }}$ averaged over $10 \mathrm{~min}, r_{e, \text { CAL-like }}, r_{e, \text { LaRC }}$, and $r_{e, \text { MAS }}$ for the five flight legs with coincidence between the ER-2 and WB-57 flight paths.

\begin{tabular}{cclcrr}
\hline \hline Flight leg & Coincidence time $(\mathrm{min})$ & \multicolumn{1}{c}{$r_{e, \text { in situ }}(\mu \mathrm{m})$} & $r_{e, \mathrm{CAL}-\text { like }}(\mu \mathrm{m})$ & $r_{e, \mathrm{LaRC}}(\mu \mathrm{m})$ & $r_{e, \mathrm{MAS}}(\mu \mathrm{m})$ \\
\hline 7 & +20 & 11-39.4, uncertainty: \pm 10.1 & - & $32.8-34.1$ & $22.3-25.9$ \\
8 & -22 & 2-66.8, uncertainty: \pm 13.7 & $22-32$ & $19.6-40$ & $31.1-38.3$ \\
12 & +14 & $22-64.2$, uncertainty: \pm 17.2 & - & $31.3-33.8$ & $23.4-25.7$ \\
13 & -14 & $11.1-59.5$, uncertainty: \pm 14.1 & - & $14.6-22.6$ & $32-39.9$ \\
14 & -22 & $13.4-61.6$, uncertainty: \pm 15 & - & $16.4-19.8$ & $32.6-39.7$ \\
\hline
\end{tabular}



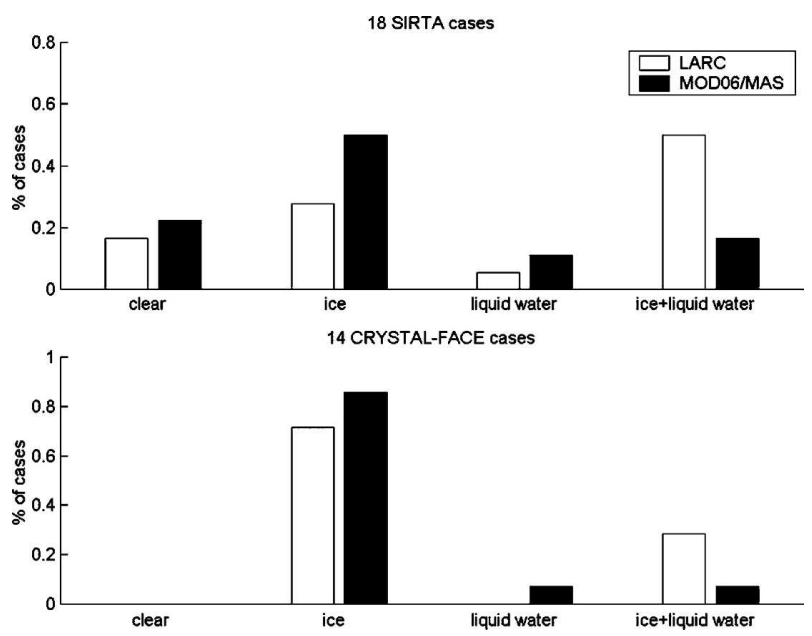

FIG. 13. Thermodynamical phase detected by the LaRC (white) and MOD06/MAS (black) methods when CALIPSO-like method leads to ice.

mate the CALIPSO-like $\tau$ more than the LaRC yet have a more accurate assessment of the cloud height (e.g., 5 March 2002 case in Table 4). Differences in the optical depths and particle sizes among all three techniques arise from differences in assumed model ice crystals, the parameterizations, and the wavelengths used. In some instances, the averages for a given case are based on different subsets of pixels because of the phase or detection discrepancies.

When the retrieval is possible, the comparison between ice particle effective radii obtained with the three methods gives encouraging results, keeping in mind that the three methods are based on different approaches and use different wavelengths. At midlatitudes, the lidar is on the ground and the imager is in space and so the CALIPSO-like method has been applied to clouds with optical thicknesses less than 3 to be sure that both instruments are sensing the same cloud. Considering such clouds, and also those thick enough to be detected by passive remote sensing methods, the agreement among the three methods is very good for $r_{e}$ retrieval, independent of the quality of the cloud altitude and temperature retrieval. The CALIPSO-like and LaRC methods have the best agreement for $r_{e}$ at midlatitudes: in $50 \%$ of the cases the difference between $r_{e, \text { CAL-like }}$ and $r_{e, \text { LaRC }}$ is less than $3 \mu \mathrm{m}$, and $r_{e, \mathrm{CAL}-\text { like }}$ is at least $5 \mu \mathrm{m}$ larger than $r_{e, \mathrm{MOD} 06}$. In the Tropics, the CALIPSO-like method can only be applied to a few cases, also leading to a relatively good agreement among the three methods: in $40 \%$ of the cases the difference between $r_{e, \text { CAL-like }}$ and $r_{e, \text { LaRC }}$ or $r_{e, \mathrm{MAS}}$ is less than $3 \mu \mathrm{m}$, and $r_{e, \mathrm{CAL}-\text { like }}$ overestimates $r_{e, \mathrm{LaRC}}$ and $r_{e, \mathrm{MAS}}$ in $40 \%$ of cases. In the Tropics, there are often large differences between $r_{e, \mathrm{CAL} \text {-like }}$ and the two other methods: those cases correspond to clouds with microphysics that are not taken into account in the LaRC and MAS methods (typically plates or spherical particles, as shown by the lidar depolarization ratio). Furthermore, there is good agreement between $r_{e \text {,LaRC }}$ and $r_{e, \text { MOD06 }}$ when the cloud optical thickness is moderate, whereas there is a discrepancy in the results for very thick clouds when the CALIPSO-like method did not give any results. Hence, it seems that whatever the method used, the estimation of the particle effective radius in strongly convective clouds in the Tropics remains a challenging task. One important conclusion concerning the particle size retrieval is the complementary role between the different methods: the lidar method is powerful for thin clouds but not for thick clouds, and vice versa for the passive methods. This complementary role is particularly important in the Tropics where clouds are often convective and vertically extended, because studies show that there is a vertical stratification of the ice particle effective radius in these clouds (Baran et al. 2003).

This study contributes to quantify the limits of the CALIPSO-like method. The method can contribute to improving the knowledge of the properties of thin and subvisible clouds where passive methods are less reliable. The CALIPSO-like method in its current state cannot be applied to derive particle effective radius and optical thickness in very thick ice clouds in the Tropics because the theoretical radiative computation used for this method is unable to reproduce negative BTDs above thick cold ice clouds as seen in the observations. Several theoretical scenarios (Chepfer et al. 2006, manuscript submitted to J. Geophys. Res.) have been studied to explain this discrepancy, such as including large variability in the temperature profile around the tropopause level, or different microphysical models, leading to the conclusion that the CALIPSO-like method using MODIS data fails in the presence of nitric acid (Chepfer et al. 2006, manuscript submitted to J. Geophys. Res.) in ice clouds that is not taken into account in the radiative transfer computations. The CALIPSO-like method applied to the real IIR/ CALIPSO channels, which are slightly different than their MODIS counterparts, should give much better results for those cases because it is not influenced by absorption by nitric acid.

Future work will consist in applying the CALIPSOlike method to the CALIPSO observations from space. This work will cover a large dataset in various latitude and time periods. The retrieval will be validated against in situ data as well as ground-based retrievals and other satellite retrievals. 
Acknowledgments. The GOES analyses were supported by the NASA Radiation Sciences Branch through the CRYSTAL-FACE project and by the U.S. Department of Energy through Interagency Agreements DE-AI02-97ER62341 as part of the Atmospheric Radiation Measurement Program. The LaRC MODIS analyses were supported by the NASA Earth Sciences Program through the LaRC Project. The authors acknowledge SIRTA for providing the ground-based lidar data.

\section{REFERENCES}

Ackerman, S. A., K. I. Strabala, W. P. Menzel, R. A. Frey, C. C. Moeller, and L. E. Gumley, 1998: Discriminating clear-sky from clouds with MODIS. J. Geophys. Res., 103, $32141-$ 32158.

Ackerman, T., and G. Stokes, 2003: The Atmospheric Radiation Measurement Program. Phys. Today, 56, 38-45.

Baran, A. J., P. D. Watts, and P. N. Francis, 1999: Testing the coherence of cirrus microphysical and bulk properties retrieved from dual-viewing multispectral satellite radiance measurements. J. Geophys. Res., 104, 31 673-31 683.

— S. Havemann, P. N. Francis, and P. D. Watts, 2003: A consistent set of single-scattering properties for cirrus cloud: tests using radiance measurements from a dual-viewing multiwavelength satellite-based instrument. J. Quant. Spectrosc. Radiat. Transfer, 79-80, 549-567.

Baum, B. A., P. F. Soulen, K. I. Strabala, M. D. King, S. A. Ackerman, W. P. Menzel, and P. Yang, 2000: Remote sensing of cloud properties using MODIS Airborne Simulator imagery during SUCCESS. II. Cloud thermodynamic phase. J. Geophys. Res., 105, 11 781-11 792.

Baumgardner, D., H. Jonsson, W. Dawson, D. O'Connor, and R. Newton, 2001: The cloud, aerosol and precipitation spectrometer (CAPS): A new instrument for cloud investigations. Atmos. Res., 59-60, 251-264.

—, H. Chepfer, G. B. Raga, and G. L. Kok, 2005: The shapes of very small cirrus particles derived from in situ measurements. Geophys. Res. Lett., 32, L01806, doi:10.1029/2004GL021300.

Chepfer, H., J. Pelon, G. Brogniez, C. Flamant, V. Trouillet, and P. H. Flamant, 1999: Impact of cirrus cloud ice crystal shape and size on multiple scattering effects: Application to spaceborne and airborne backscatter lidar measurements during LITE mission and E LITE campaign. Geophys. Res. Lett., 26, 2203-2206.

Chiriaco, M., H. Chepfer, V. Noël, A. Delaval, M. Haeffelin, P. Dubuisson, and P. Yang, 2004: Improving retrievals of cirrus cloud particle size coupling lidar and 3-channel radiometric techniques. Mon. Wea. Rev., 132, 1684-1700.

,$- \ldots$, M. Haeffelin, and P. Drobinski, 2006: Dual lidar observations at $10.6 \mu \mathrm{m}$ and $532 \mathrm{~nm}$ for retrieving semitransparent cirrus cloud properties. J. Appl. Meteor. Climatol., 45, $537-555$.

Derber, J. C., D. F. Parrish, and S. J. Lord, 1991: The new global operational analysis system at the National Meteorological Center. Wea. Forecasting, 6, 538-547.

Dubuisson, P., J. C. Buriez, and Y. Fouquart, 1996: High spectral resolution solar radiative transfer in absorbing and scattering media: Application to the satellite simulation. J. Quant. Spectrosc. Radiat. Transfer, 55, 103-126.
-, V. Giraud, O. Chomette, H. Chepfer, and J. Pelon, 2005: Fast radiative transfer modeling for infrared imaging radiometry. J. Quant. Spectrosc. Radiat. Transfer, 95, 201-220.

Haeffelin, M., and Coauthors, 2005: SIRTA, a ground-based atmospheric observatory for cloud and aerosol research. Ann. Geophys., 23, 253-275.

Havemann, S., and A. J. Baran, 2001: Extension of T-matrix to scattering of electromagnetic plane waves by non-axisymmetrics dielectric particles: Application to hexagonal cylinder. J. Quant. Spectrosc. Radiat. Transfer, 70, 139-158.

Heymsfield, A. J., 1975: Cirrus uncinus generating cells and the evolution of cirriform clouds. Part I: Aircraft observations of the growth of the ice phase. J. Atmos. Sci., 32, 799-807.

__ 1993: Microphysical structure of stratiform and cirrus clouds. Aerosol Cloud Climate Interactions, P. V. Hobbs, Ed., International Geophysics Series, Vol. 54, Academic Press.

— size spectrum of ice clouds in terms of the ambient temperature and the ice water content. J. Atmos. Sci., 41, 846-855.

Hock, T. F., and J. L. Franklin, 1999: The NCAR GPS dropwindsonde. Bull. Amer. Meteor. Soc., 80, 407-420.

Intrieri, J., G. L. Stephens, W. L. Eberhard, and T. Uttal, 1993: A method for determining cirrus cloud particle sizes using lidar and radar backscatter technique. J. Appl. Meteor., 32, 10741082.

Intrieri, J. M., W. L. Eberhard, T. Uttal, J. A. Shaw, J. B. Snider, Y. Han, B. W. Orr, and S. Y. Matrosov, 1995: Multiwavelength observations of a developing cloud system: The FIRE II 26 November 1991 case study. J. Atmos. Sci., 52, 40794093.

Jensen, E., D. Starr, and O. B. Toon, 2004: Mission investigates tropical cirrus clouds. Eos, Trans. Amer. Geophys. Union, 85, 45-50.

King, M. D., and Coauthors, 2003: Cloud and aerosol properties, precipitable water, and profiles of temperature and humidity from MODIS. IEEE Trans. Geosci. Remote Sens., 41, 442458.

_, S. Platnick, P. Yang, G. T. Arnold, M. A. Gray, J. C. Riedi, S. A. Ackerman, and K. N. Liou, 2004: Remote sensing of liquid water and ice cloud optical thickness and effective radius in the Arctic: Application of airborne multispectral MAS data. J. Atmos. Oceanic Technol., 21, 857-875.

Krupp, C., 1991: Holographic measurements of ice crystals in cirrus clouds during the International Cloud Experiment ICE 1989. Report of the Fourth ICE/EUCREX Workshop, Lille, France, Laboratoire d'Optique Atmosphérique, USTL.

Liou, K. N., 1986: Influence of cirrus clouds on weather and climate processes: A global perspective. Mon. Wea. Rev., 114, $1167-1199$

Mace, G. G., K. Sassen, S. Kinne, and T. P. Ackerman, 1998: An examination of cirrus cloud characteristics using data from millimeter wave radar and lidar: The 24 April SUCCESS case study. Geophys. Res. Lett., 25, 1133-1136.

- , Y. Zhang, S. Platnick, M. D. King, P. Minnis, and P. Yang, 2005: Evaluation of cirrus cloud properties derived from MODIS data using cloud properties derived from groundbased observations collected at the ARM SGP site. J. Appl. Meteor., 44, 221-240.

Macke, A., J. Mueller, and E. Raschke, 1996: Single scattering properties of atmospheric ice crystals. J. Atmos. Sci., 53, 2813-2825.

Matrosov, S. Y., 1999: Retrievals of vertical profiles of ice cloud microphysics from radar and IR measurements using tuned 
regressions between reflectivity and cloud parameters. $J$. Geophys. Res., 104, 16 741-16 753.

McFarquhar, G. M., and A. J. Heymsfield, 1996: Microphysical characteristics of three anvils sampled during the Central Equatorial Pacific Experiment. J. Atmos. Sci., 53, 2401-2423.

Menzel, W. P., W. L. Smith, and T. R. Stewart, 1983: Improved cloud motion wind vector and altitude assignment using VAS. J. Climate Appl. Meteor., 22, 377-384.

Minnis, P., and Coauthors, 1995: Cloud optical property retrieval (subsystem 4.3). Clouds and the Earth's Radiant Energy System (CERES) algorithm theoretical basis document, volume III: Cloud analyses and radiance inversions (subsystem 4), NASA Rep. RP 1376, Vol. 3, 135-176.

— D. P. Garber, and D. F. Young, 1998: Parameterizations of reflectance and effective emittance for satellite remote sensing of cloud properties. J. Atmos. Sci., 55, 3313-3339.

- , Y. Yi, J. Huang, and J. K. Ayers, 2005: Relationships between radiosonde and RUC-2 meteorological conditions and cloud occurrence determined from ARM data. J. Geophys. Res., 110, D23204, doi:10.1029/2005JD006005.

Mishchenko, M. I., 1991: Light scattering by randomly oriented axially symmetric particles. J. Opt. Soc. Amer., 8A, 871-882.

Noel, V., H. Chepfer, G. Ledanois, A. Delaval, and P. H. Flamant, 2002: Classification of particle effective shape ratios in cirrus clouds based on lidar depolarization ratio. Appl. Opt., 41, 4245-4257.

Pilewskie, P., and S. Twomey, 1987: Discrimination of ice from water in clouds by optical remote sensing. Atmos. Res., 21, 113-122.

Platnick, S., M. D. King, H. Gerber, and P. V. Hobbs, 2001: A solar reflectance technique for cloud retrievals over snow and ice surfaces. J. Geophys. Res., 106, 15 185-15 199.

—, M. D. King, S. A. Ackerman, W. P. Menzel, B. A. Baum, J. C. Riedi, and R. A. Frey, 2003: The MODIS cloud products: Algorithms and examples from Terra. IEEE Trans. Geosci. Remote Sens., 41, 459-473.

Platt, C. M. R., 1973: Lidar and radiometric observations of cirrus clouds. J. Atmos. Sci., 30, 1191-1204.

_ J. D. Spinhirne, and W. D. Hart, 1989: Optical and microphysical properties of a cold cirrus cloud: Evidence for regions of small particles. J. Geophys. Res., 94, 11 151-11 164.

Radel, G., C. J. Stubenrauch, R. Holz, and D. L. Mitchell, 2003: Retrieval of effective ice crystal size in the infrared: Sensitivity study and global measurements from TIROS-N Operational Vertical Sounder. J. Geophys. Res., 108, 4281, doi:10.1029/2002JD002801.

Randall, D., B. Albrecht, S. Cox, D. Johnson, P. Minnis, W. Rossow, and D. Starr, 1996: On FIRE at ten. Advances in Geophysics, Vol. 38, Academic Press.

Raschke, E., J. Schmetz, J. Heitzenberg, R. Kandel, and R. Saun- ders, 1990: The International Cirrus Experiment (ICE): A joint European effort. ESA J., 14, 193-199.

- , P. H. Flamant, Y. Fouquart, P. Hignet, H. Hisaka, P. R. Jonas, H. Sundquist, and P. Wendling, 1998: Cloud-radiation studies during the European Cloud Radiation Experiment (EUCREX). Surv. Geophys., 19, 89-138.

Sherwood, S. C., J.-H. Chae, P. Minnis, and M. McGill, 2004: Underestimation of deep convective cloud tops by thermal imagery. Geophys. Res. Lett., 31, L11102, doi:10.1029/ 2004GL019699.

Stephens, G. L., S. C. Tsay, P. W. Stackhouse, and P. J. Flatau, 1990: The relevance of the microphysical and radiative properties of cirrus clouds to climate and climate feedback. $J$. Atmos. Sci., 47, 1742-1753.

Takano, Y., and K. N. Liou, 1989: Solar radiative transfer in cirrus clouds. Part I: Single-scattering and optical properties of hexagonal ice crystals. J. Atmos. Sci., 46, 3-18.

Toon, O. B., and R. C. Miake-Lye, 1998: Contrails and Cloud Effects Special Study (SUCCESS). Geophys. Res. Lett., 25, 1109-1112.

Trepte, Q., P. Minnis, and R. F. Arduini, 2002: Daytime and nighttime polar cloud and snow identification using MODIS data. Optical Remote Sensing of the Atmosphere and Clouds III, H.-L. Huang, D. Lu, and Yasuhiro Sasano, Eds., International Society for Optical Engineering (SPIE Proceedings Vol. 4891), 449-459.

Wendling, P., R. Wendling, and H. K. Weickmann, 1979: Scattering of solar radiation by hexagonal ice crystals. Appl. Opt., 18, 2663-2671.

Winker, D. M., J. R. Pelon, and M. P. McCormick, 2003: The CALIPSO mission: Spaceborne lidar for observation of aerosols and clouds. Lidar Remote Sensing for Industry and Environment Monitoring III, U. N. Singh, T. Itabe, and Z. Liu, Eds., International Society for Optical Engineering (SPIE Proceedings Vol. 4893), 1-11.

Yang, P., and K. N. Liou, 1996a: Finite-difference time domain method for light scattering by small ice crystals in threedimensional space. J. Opt. Soc. Amer., 13, 2072-2085.

- , and $-1996 \mathrm{~b}$ : Geometric optics integral equation method for light scattering by nonspherical ice crystals. Appl. Opt., 35, 6568-6584.

,-- , M. I. Mishchenko, and B.-C. Gao, 2000: An efficient finite difference time domain scheme for light scattering by dielectric particles: Application to aerosols. Appl. Opt., 39, 3727-3737.

— B. Bao, B. A. Baum, Y. X. Hu, W. J. Wiscombe, S. Tsay, and D. M. Winker, 2001: Radiative properties of cirrus clouds in the infrared $(8-13 \mu \mathrm{m})$ spectral region. J. Quant. Spectrosc. Radiat. Transer, 70, 473-504.

Young, A. T., 1980: Revised depolarization corrections for atmospheric extinction. Appl. Opt., 19, 3427-3428. 